\title{
Development of geopolymer mortar under ambient temperature for in situ applications
}

\author{
Mohammed Haloob Al-Majidi a, Andreas Lampropoulos ${ }^{\mathrm{a}}$, Andrew Cundy ${ }^{\mathrm{a}}$, Steve Meikle ${ }^{\mathrm{b}}$ \\ a School of Environment and Technology, University of Brighton, Moulsecoomb, Brighton BN2 4GJ, UK \\ ${ }^{\mathrm{b}}$ School of Pharmacy and Biomolecular Sciences, University of Brighton, Moulsecoomb, Brighton BN2 4GJ, \\ UK
}

\section{ABSTRACT}

Geopolymer concrete technology involves production of more environmentally friendly waste material-based concrete which could be a viable solution for conventional concrete replacement. Typical fly ash-based geopolymer concrete however requires high temperature curing treatment in order to develop sufficient early strength properties, which is considered a severe limitation for cast-in-place concrete applications. Most previous studies on geopolymer concrete have focused on the properties of concretes pre-hardened by heat curing and/ or by aggressive chemical treatment (e.g. alkali activation using concentrated sodium hydroxide $(\mathrm{NaOH}))$. The current study presents an extensive experimental investigation on the mechanical and microstructural properties of geopolymer concrete mixes prepared with a combination of fly ash and slag cured under ambient temperature. 'User friendly' geopolymer mixes were produced using fly ash (FA) and Ground Granulated Blast furnace Slag (GGBS) mixed together with potassium silicate with molar ratio equal to 1.2 (as the activator) and water. The results indicated that heat curing treatment can be avoided by partial replacement of fly ash with slag. The compressive strength of the examined mixes was found to be in the range of $40-50 \mathrm{MPa}$ for $40 \%$ and $50 \%$ GGBS replacement mixtures respectively. Moreover, the flexural and direct tensile strengths of geopolymer mixes are considerably improved as the GGBS content is increased. Based on FTIR and SEM/EDS analysis, the inclusion of a higher content of GGBS resulted in a denser structure by formation of more hydration products.

Keywords: Fly ash, slag, ambient temperature, user friendly geopolymer mortar 


\section{$1 \quad$ Introduction}

There are many environmental issues associated with the production of Ordinary Portland cement (OPC), such as consumption of $5 \%$ of natural resources, and generation of 5-7 \% of total global anthropogenic carbon dioxide emissions [1-4]. This has led to an urgent need for the development of alternative materials that may provide technically viable alternative solutions to conventional cementitious concrete, with more favourable environmental credentials. Geopolymer concrete manufacture is one of the most promising techniques which has been developed in the last few years. Utilization of geopolymer materials can reduce $80 \%$ of greenhouse gas emissions associated with material production, and overcome issues related to cement production and unregulated disposal of industrial materials by recycling these materials in geopolymer manufacture [5-7].

Geopolymers are inorganic by-product materials, rich in silicon (Si) and aluminium (Al) that react with alkaline activators to form three dimensional polymeric chains of sialate and poly(sialate) (Si-O-Al-O) [8-11]. Previous research indicates that the chemical reactions and strength development of geopolymer concrete are affected by number of parameters such as chemical activator composition and dosage, raw materials, and curing conditions [10, 12]. Al-Otaibi [13] noted that the type and dosage of activator used are particularly important in slag-based geopolymer concrete production. According to this study, the strength of geopolymer concrete is improved as dosage and silicate modulus of the activator are increased. Davidovits [14] reported that a metakaolinite-based geopolymer with potassiumcontaining alkaline activator showed double the compressive strength of the same geopolymer mix with sodium alkaline activating solution. Lloyd et al., [15] also noted that, based on microstructural observations, the use of silicate-based activators resulted in a more homogeneous microstructure compared to the mixes activated with a sodium hydroxide $(\mathrm{NaOH})$ based solution, and improved compressive strength.

Fly ash (FA) and Ground Granulated Blast furnace Slag (GGBS) are two types of calcium aluminosilicate solid waste materials commonly used in geopolymer concrete. The main reaction product of alkali-activated cements for GGBS is calcium silicate hydrate (C-S-H) while for FA it is amorphous hydrated alkali-aluminosilicate [16]. Alkali activated slag has high strength but issues related to rapid 
setting and insufficient workability along with high values of dry shrinkage have been reported [17]. In contrast, FA based geopolymer mortars cured under ambient temperatures usually exhibit slower early strength development and setting time, which is likely to be due to a low content of iron oxide, calcium hydroxide $\left(\mathrm{Ca}(\mathrm{OH})_{2}\right)$, and reactive silica [18]. These mortars however showed identical compressive strength (62-66 MPa) after 24 hour curing at $60-75{ }^{\circ} \mathrm{C}[19]$. High temperature curing for at least 6 hours is typically recommended for FA based geopolymer concrete in order to accelerate the pozzolanic reaction and develop the mechanical properties [20, 21]. Van Jaarsveld et al., [22] studied the effect of various curing temperatures on the compressive strength of FA geopolymer concrete, and based on this study, double strength was achieved when the curing temperature was increased to between $50^{\circ} \mathrm{C}$ and $80^{\circ} \mathrm{C}$ compared to the respective value at $30^{\circ} \mathrm{C}$. However, heat curing treatment leads to increased cost and practical issues, preventing in situ application of geopolymer concrete at large scale.

There are a few published studies on geopolymer mixes with a variant combination of FA and GGBS in the mixture $[9,16,17,23-25]$ and in most of these studies promising results were achieved. However, in these studies high volumes and concentrations of corrosive sodium silicate and/or sodium hydroxide have been used leading to geopolymer products with potential health and worker safety issues during application [14]. Davidovits et al [26], propose a user friendly geopolymeric method in order to improve the strength of geopolymer cement as well as reduce costs by avoiding thermal activation and promoting easier handling applications. To date, there are not any published studies on the mechanical performance of 'user friendly' geopolymer mortars, and only mineralogical and microstructural analyses of the geopolymer cement paste of these mixes have been conducted.

The current study aims to investigate the main parameters affecting the behaviour of this material and to optimize its mechanical performance. An extensive experimental study has been conducted on FA and GGBS based user friendly geopolymer mortars cured under ambient temperature with mechanical properties comparable to FA-only based mixtures cured under elevated temperature. Fresh geopolymer mortar properties were examined through workability and setting time tests, while the mechanical performance of the hardened mortar was evaluated by compressive, direct tensile and flexural strength tests. Moreover, the microstructure of the examined mixes was assessed by Scanning Electron 
Microscopy (SEM), Energy Dispersive Spectroscopy (EDS), Fourier Transform Infrared Spectroscopy (FTIR), thermal analysis Differential Scanning Calorimetry (DSC), and porosity measurements.

\section{Experimental Program}

\subsection{Materials and mix-design}

FA conforming to BS EN 450 - 1 [27] fineness category $S$ was used as the main binder in this study. This was partially replaced by GGBS in order to produce FA and GGBS based geopolymer materials. Silica sand with particle size less than $0.5 \mathrm{~mm}$ and chemical composition as shown in Table1 was used as fine aggregate. A particle size analyser (Malvern mastersizer 2000) was used to determine the particle size distribution. Polycarboxylatebased superplasticizer meeting the requirements of BS EN 934-2 [28] was also used.

Five different mixtures of geopolymer mortar proportions were examined with various ratios of GGBS to total binder $(10 \%, 20 \%, 30 \%, 40 \%$ and $50 \%$, Table 2$)$. Based on preliminary experimental studies undertaken during the current project, the optimum mix design (in terms of mechanical strength and workability) was achieved using water, alkaline activator and superplasticizer contents equal to $25 \%, 12 \%$, and $1 \%$ of the total binder respectively. The examined mixtures were designed based on a previously published study on FA based geopolymer mortars, with total binder content kept constant for all mixtures at $775 \mathrm{~kg} / \mathrm{m}^{3}$ [29]. The molar ratio of potassium silicate solution $\left(\mathrm{K}_{2} \mathrm{SiO}_{3}\right.$-used as a chemical activator) remained at the same level for all mixtures at 1.25.

\subsection{Mixing procedure and specimens preparation}

Potassium hydroxide pearl ( $85 \%$ purity) and commercially available potassium silicate solution (Molar ratio $\mathrm{SiO}_{2} / \mathrm{K}_{2} \mathrm{O}$ equal to 2.23 , water content equal to $45-65$ wt.\%, specific gravity $1.6 \mathrm{~g} / \mathrm{mL}$ ) were used as alkali activators. The alkali activator solution was prepared by the dilution of potassium hydroxide pellets in distilled water in a fume cupboard. The solution was left for 24 hours to cool down to room temperature before mixing with potassium silicate solution (mass of Potassium silicate solution/Potassium hydroxide solution equal to 2.5 ), to form a solution modulus equal to 1.25 . 
For the trial mixing of geopolymer mortars, a $5 \mathrm{~L}$ Hobart mixer was used, while for the mixing of the examined specimens a Zyklos $75 \mathrm{~L}$ mixer was used (Pan Mixer ZZ $75 \mathrm{HE}$ ). The mixing procedure proposed by GEOASH [26] was used in this study. Alkali activator potassium silicate solution was prepared in advance and mixed with water and superplasticizer 5 minutes before addition to the solid materials. The binder (FA and GGBS) was dry mixed for 5 minutes at low speed $(140 \pm 5 \mathrm{rpm})$ to ensure adequate mixing. The alkali activator potassium silicate solution was then added to the powder and the mixer run at medium speed for 5 minutes. Finally, sand was added to the mixer, and the mixer run for a further 3 minutes to give a total mixing time of 13 minutes. For the current study the following specimens were examined:

- Forty-eight cubic specimens with $50 \mathrm{~mm}$ side, twelve specimens for each mixture, for compressive tests.

- Thirty-six prismatic specimens having dimensions $75 \mathrm{~mm} \times 75 \mathrm{~mm} \times 285 \mathrm{~mm}$, nine specimens for each mixture, for flexural test (Fig. 1a).

- Thirty-six dog bone shape specimens having $25 \times 25 \mathrm{~mm}^{2}$ mid-cross section, for direct tensile tests (Fig.1b and 1c).

- Eight cylindrical specimens having dimensions $20 \mathrm{~mm}$ diameter and $50 \mathrm{~mm}$ length, two specimens for each mixture, for porosity measurement.

Table 3 shows the number and types of specimens prepared. Flowability and setting time tests on fresh geopolymer mortars were also conducted. All the examined specimens were de-molded twenty-four hours after casting, and the specimens were covered with plastic film to avoid evaporation of water. The specimens were stored at room temperature for curing $\left(21-23^{\circ} \mathrm{C}\right)$ until the day of testing.

\section{Experimental equipment and test procedures}

\subsection{Fresh geopolymer concrete}

Two different tests were used for fresh state mortar: setting time and workability. 


\subsubsection{Setting time}

The setting times (initial and final) of the fresh geopolymer mortar were evaluated using a vicat needle as described in BS EN 480-2:2006 [30]. Penetration distances were measured every 5 minutes due to rapid setting of the examined mixes. The determined values were calculated as the average of two separate tests under room temperature curing conditions $\left(21-23^{\circ} \mathrm{C}\right)$.

\subsubsection{Flowability test}

This test was conducted according to EN 1015-3 [31] and ASTM C 1437-07 [32]. Flow tests were conducted immediately after mixing, and the cone lifted straight vertically to allow free flow of the mixture without any jolting. Details of the mini slump measurements have been reported in previous studies $[33,34]$. Each mix was tested twice.

\subsection{Hardened geopolymer concrete}

To evaluate strength characteristics of hardened geopolymer mortar, compression, direct tensile and flexural strengths tests were carried out.

Compressive strength tests were performed under a loading rate of $45 \mathrm{KN}$ per minute according to ASTM C109 [35].

Flexural strength tests were performed according to ASTM C $293-02$ [36] using a simple beam with centre loading. An Instron universal test machine was used and the setup is presented in Fig. 1 a.

Geopolymer tensile performance was evaluated through direct tensile tests according to AASHTO T132 [37]. The examined dog bone-shaped briquettes had a thickness of $25 \mathrm{~mm}$, a length of $76 \mathrm{~mm}$ and a mid-length cross sectional area of $625 \mathrm{~mm}^{2}$ (Fig. 1b). Special selfaligning grips were used for the direct tensile tests to ensure uniform stress distribution (Fig. 1b). The extension of the specimens during the testing was monitored using Linear Variable Differential Transformers (LVDTs) attached to the specimens in order to exclude any induced slip at the grips (Fig. 1c). The direct tensile tests were performed under a displacement rate of $0.4 \mathrm{~mm}$ per minute. 


\subsection{Microstructural analysis}

Microstructural analyses were performed on geopolymer paste and mortar samples via porosity, SEM, FTIR and thermal analysis. For porosity measurements cylindrical specimens with $20 \mathrm{~mm}$ diameter and $50 \mathrm{~mm}$ height were used. Two specimens for each of the examined mixes were tested at 28 days after casting following the procedure described in previously published studies [38, 39].

For SEM analysis, geopolymer mortar samples were coated with carbon after 7 and 28 days curing and imaged using a Leo S420 stereoscan scanning electron microscope with an accelerating voltage range of 1-30 kV. FTIR analysis was carried out on fine powder generated by grinding the 28 days geopolymer paste sample to reduce its particle size. Measurements were conducted using a Mettler Toledo spectrometer. For thermal analysis, tests were conducted using a Mettler Toledo differential scanning calorimeter. During this test the binder percentage was kept constant as in the mixtures and total sample mass was around $20 \mathrm{~g}$; mixing was performed manually; and sample loading time was around 20 minutes.

\section{$4 \quad$ Results and discussion}

\subsection{Primary particle size and agglomerate size}

FA consists predominantly of spherical primary particles, whereas GGBS particles are more angular (Fig. 2). The geometry and the size of the FA and GGBS particles was analysed with a laser particle size analyser and the results are presented in Fig. 3. Table 4 shows the most common statistics used to analyse the particle size of the material: the mean of the particle size (d (0.5)), 10\% (d (0.1)) and 90\% (d (0.9)) of the total volume of particle size smaller than particular size diameter. The volume-mean particle sizes ( $\mathrm{d}(0.5))$ of the FA and GGBS are 10.6 and $14.3 \mu \mathrm{m}$, respectively. FA particles give a finer particle size distribution than slag, which could improve mortar formation.

\subsection{Setting time}

Setting time tests were performed to investigate the effects of GGBS content on FA and GGBS based geopolymer mortar. Geopolymer mixes with GGBS to binder ratios of $10 \%$, $20 \%, 30 \%, 40 \%$ and $50 \%$ were examined. In this test, two measurements were taken for the initial and final setting time as proposed by BS EN480-2:2006 [30]. Initial setting time was measured from completion of mixing until the time at which the needle penetrated to a 
distance of $4 \mathrm{~mm}$ from the base of the plate. Final setting time was measured at the point at which the needle penetrated to a respective distance of $2.5 \mathrm{~mm}$ [30].

The results of Fig. 4 indicate that the setting time was considerably affected by the GGBS content in the mix. Based on a previous study [24], the setting time for FA based geopolymer without GGBS has been found to be around 1500 minutes. Setting time was significantly reduced by incorporating GGBS in the mixture, e.g. the initial and final setting times of mixtures having $10 \%$ GGBS were reduced to 80 minutes and 150 minutes respectively. As the GGBS content in the mix was increased, the total setting time was considerably reduced. The initial and final setting times for $20 \%$ GGBS content were 58 minutes and 120 minutes while for $30 \%$ GGBS these reduced to 42 minutes and 80 minutes. The setting time further slightly decreased when increasing GGBS over total binder ratio from $30 \%$ to $40 \%$. This is in agreement with previous investigations on the effect of GGBS content on setting times of FA geopolymer mortar with sodium silicate activator. Lee and Lee [23] found that the hydration reaction of FA based geopolymer materials was accelerated as the GGBS, and subsequently $\mathrm{CaO}$ content, was increased in the mix. Also, Nath and Sarker [25] reported that the use of slag resulted in an acceleration of the setting time of geopolymer mixes.

\subsection{Flowability of geopolymer mortar}

The relative slump of the geopolymer mortar using varying GGBS to FA ratios is presented in Fig.5. The measurements indicate that the $10 \mathrm{~S}$ mixture was very fluid and exceeded the flow table limit of $255 \mathrm{~mm}$. The workability of the geopolymer mixture was reduced as GGBS content increased. The reduction in relative slump was $36 \%, 55 \%, 62 \%$, and $65 \%$ for the 20S, $30 \mathrm{~S}, 40 \mathrm{~S}$ and $50 \mathrm{~S}$ mixtures compared to the experimental results for the $10 \mathrm{~S}$ mixture. This is likely a consequence of differences in the physical properties and chemical reactions of the mixtures. As the GGBS content is increased, the number of angular particles is increased and the spherical particles of FA are reduced (e.g. Fig. 2). The spherical shape can help to improve the Flowability of the mortar mixture. Also, admixing GGBS and FA offers more reactive material, giving fast setting and reducing the workability. 


\subsection{Compressive strength}

\subsubsection{Curing at ambient temperature}

As the GGBS content in the mix was increased, the compressive strength was improved even at early curing ages (Fig. 6). The three day mean compressive strengths were 2.9 MPa, 10.4 MPa, 13.7 MPa, 18.6 MPa and 25.9 MPa for 10S, 20S, 30S, 40S and 50S mixtures respectively. At 28 days, mixtures having $20,30,40$ and $50 \%$ wt. ratio of GGBS to the total binder achieved 65, 133, 140 and $162 \%$ higher strength compared to the strength of the $10 \mathrm{~S}$ mixture, respectively. This is due to infilling of the porous microstructure of the geopolymer mortar by formation of more hydration products, following the inclusion of the highly reactive slag particles (discussed further in section 4.8). Weiguo et al. [40] examined varying GGBS/FA ratios by weight $(0,30,40,50,60,70$ and $100 \%)$, with sodium silicate and sodium hydroxide as the alkaline activator. The main findings of this study indicated that as the GGBS content was increased, the compressive and flexural strength of the mix was improved.

\subsubsection{Comparisons with heat treated specimens}

In this section the effect of curing temperature on the compressive strength of geopolymer mixes with FA and GGBS has been investigated. The compressive strength results of $50 \mathrm{~S}$ mixture samples cured under elevated temperature have been compared with respective results of specimens made of the same mix and cured under room temperature (Fig. 7). The elevated temperature curing process involved resting of the samples for $24 \mathrm{~h}$ at room temperature after casting, followed by heat curing at $60^{\circ} \mathrm{C}$ for $24 \mathrm{~h}$, and then storage at room temperature until testing. At early age, heat curing treatment has a great effect on the strength of FA and GGBS based geopolymer. The 3 day compressive strength of the geopolymer sample cured under elevated temperature is almost double that of the ambient temperature cured sample. This finding is in agreement with the results of a previous study [41] where curing under elevated temperature was found to be beneficial in accelerating strength development. Görhan et al. [42] highlighted that curing under elevated temperature leads to an increment of the compressive strength without significant effect on the physical characteristics. 
Based on the results of the current study (Fig. 7), it can also be observed that the 28days compressive strength of the specimens cured under room temperature is very close to the respective results of the heat cured specimens.

\subsection{Direct tensile test}

The direct tensile strength of geopolymer mixes with varying GGBS content (10\% to 40 $\%$ wt. of the total binder) cured under ambient temperature was determined at 7 and 28 curing days as shown in Fig. 8. Increasing the GGBS content had a positive effect on the tensile strength at both ages. The results indicated that the specimens with $40 \%$ GGBS had the highest direct tensile strength which was around $3 \mathrm{MPa}$ at 28 days. There are no published studies in the literature performing similar tests of direct tensile strength on geopolymer samples, and there are only a few other studies where splitting tensile strength results of geopolymer concrete are presented. Rashad [43] studied the mechanical strength of geopolymer concretes with varying ratios of FA to total binder (FA and GGBS) $(100 \%, 95 \%$ and 85\%) using a mixture of $\mathrm{NaOH}$ and sodium silicate as an activator. The results indicated that the split tensile strength was increased as the slag content increased, which is in agreement with the findings of the current study.

\subsection{Flexural Strength}

Flexural strength tests were performed using prismatic specimens (Fig. 1a) with span length (between the supports of the specimens) of $225 \mathrm{~mm}$. For each mix, three specimens were tested at each age, and the flexural strength is calculated using the average value.

Variations in flexural strength with increasing GGBS content (at curing ages of 7, 14 and 28 days) are shown in Fig. 9. The ultimate flexural strength of geopolymer mortar was considerably increased by increasing the GGBS content, at all ages. At 7 days, the flexural strength of the $10 \mathrm{~S}$ mix was $0.93 \mathrm{MPa}$. The flexural strength was improved by $0.6 \mathrm{MPa}, 1.3$ $\mathrm{MPa}$ and $2 \mathrm{MPa}$ as the GGBS content was increased from $10 \%$ to $20 \%, 30 \%$ and $40 \%$, respectively. Flexural strength developed further with longer curing times, with the flexural strength increasing at 14 and 28 days by $100 \%-245 \%$, $94 \%-206 \%, 48 \%-121 \%$ and $26 \%-99$ $\%$ for $10 \mathrm{~S}, 20 \mathrm{~S}, 30 \mathrm{~S}$ and $40 \mathrm{~S}$ mixtures respectively, compared to the flexural strength values at 7 days. 


\subsection{Porosity}

Fig. 10 plots the porosity of the geopolymer mortars at 28 days. The results show that increasing GGBS content leads to a reduction in apparent porosity in the geopolymer mortar cured at room temperature. Total porosity after 28 days curing of the $10 \mathrm{~S}$ mixture was around $30 \%$. As the GGBS content was increased, the porosity was reduced to $23 \%, 21 \%$ and 18.3 $\%$ for 20S, $30 \mathrm{~S}$ and $40 \mathrm{~S}$ mixtures, respectively. The reduction in porosity identified in specimens with higher contents of GGBS can be attributed to the nature of the gel type forming in the binder. The calcium ions present in GGBS particles (see Table 1) may enter into the FA-rich system (with Si-O-Al-O structure) to form a calcium aluminium silicate hydrate gel (C-(A)-S-H), also unreacted finer GGBS particles act as a reinforcing agent. This infills the geopolymer matrix, reduces the porosity and improves the mechanical strength.

\subsection{Scanning Electronic Microscopy (SEM) and Energy Dispersive Spectroscopy (EDS)}

Sub-samples taken from $50 \mathrm{~mm}^{3}$ cubes were used to examine sample microstructure after 7 and 28 days. EDS microanalysis on specific sample areas was used to provide semiquantitative $\mathrm{Si}, \mathrm{Al}, \mathrm{Ca}, \mathrm{Na}, \mathrm{O}, \mathrm{Mg}$ and Fe data from an average of three different areas in the sample, and data are given in Table 5.

Based on the EDS analysis the main contributors to the geopolymer matrix are the glassy FA particles (supplying $\mathrm{Si}$ and $\mathrm{Al}$ ), the GGBS (supplying $\mathrm{Ca}$ ) and the alkali-activation solution (potassium silicate) (Fig.11). To compare the microstructure of different GGBS to binder ratios of geopolymer, two mixes of $10 \%$ and $40 \%$ GGBS to total binder were imaged (Fig. 12 and 13). Figure 12 shows the area on a surface of $10 \%$ GGBS at curing ages of 7 days and 28 days at $\times 3000, \times 10000$ and $\times 20000$ magnification. The micrographs of the 105 mixture show a high proportion of un-reacted FA spheres, and agglomerated GGBS particles remaining in the early age matrix. After 28 days curing, the geopolymer microstructure shows amorphous microspheres, and partially reacted FA spheres appear in the matrix (Fig. 12). At higher magnification, geopolymer samples show different microstructures with an increasing slag content, which forms a denser matrix than using $10 \%$ GGBS. Glassy crusts covering FA particles can be observed, as a result of reactions on the surface of the particles (Fig.13 (a-e)). In the geopolymerization method, the development of the geopolymer matrix depends on reactions at the external rim of the particles, producing reaction products which surround and 
cement the particles, rather than dissolution of the particles [44]. The presence of calcium in the GGBS is confirmed by the EDS analysis (at around 38 wt. \%, Table 6), showing that increasing the amount of GGBS significantly increased the calcium content in the mixture, leading to the formation of a calcium alumino-silicate hydrate (C-A-S-H) gel [25].

Therefore, inclusion of GGBS introduced additional calcium bearing compounds and contributed to additional binding products, which improved the compressive strength, reduced porosity and modified the setting behaviour of geopolymeric gels at early ages. This enabled the formation of a more compact gel structure and consequently improved mechanical properties.

\subsection{Fourier Transform Infrared Spectroscopy (FTIR)}

Fourier Transform Infrared Spectroscopy (FTIR) is a chemical analysis method which searches for the reaction zones of $\mathrm{Si}-\mathrm{O}$ and $\mathrm{Al}-\mathrm{O}$ in order to identify the degree of geopolymerization and formation of reaction products in the various geopolymer mixtures [10]. The current study focuses on specific spectral zones: the bands at $1200-900 \mathrm{~cm}^{-1}$ corresponding to the asymmetric stretching vibration of (Si-O-Si) and (Si-O-Al); the bands assigned around $3350 \mathrm{~cm}^{-1}$ corresponding to the stretching vibrations of $\mathrm{H}-\mathrm{O}-\mathrm{H}$ bonds; and the band around $1645 \mathrm{~cm}^{-1}$ which relates to the bending vibration of the $-\mathrm{OH}$ groups of the hydrated reaction products associated with water $[45,46]$.

The infrared spectroscopic results for the raw materials (FA and GGBS) are presented in Fig.14a. The stretching vibration mode of Si-O-T (T represents $\mathrm{Si}$ or $\mathrm{Al}$ ) was found at 903 $\mathrm{cm}^{-1}$ for GGBS and at $1007 \mathrm{~cm}^{-1}$ for FA, and are consistent with (a) the variations in the chemical structure as indicated in the EDS analysis and (b) the glassy structure of these materials. The reduction of the wavenumber of this band corresponds to lower degrees of crosslinking of the amorphous phase of the raw materials, induced by increased calcium content [47]

The FTIR spectra of the geopolymer paste samples show clear differences compared to the respective spectrum of the FA and GGBS. Fig.14b plots the FT-IR results after 28 days for varying GGBS to binder weight ratios (10\%-40\%). The Si-O-Si stretching vibration of FA occurred at $1007 \mathrm{~cm}^{-1}$. However, the corresponding stretching vibration of geopolymer paste has shifted to $959 \mathrm{~cm}^{-1}, 952 \mathrm{~cm}^{-1}, 951 \mathrm{~cm}^{-1}$ and $947 \mathrm{~cm}^{-1}$ for $10 \mathrm{~S}, 20 \mathrm{~S}, 30 \mathrm{~S}$ and $40 \mathrm{~S}$ mixtures, respectively. Based on these values, increasing the GGBS content causes structural changes 
in the examined mixes, which is attributed to the formation of $\mathrm{C}-\mathrm{S}-\mathrm{H}$ with $\mathrm{N}-\mathrm{A}-\mathrm{S}-\mathrm{H}$ type gels and to a subsequent reduction of the amount of Al. These changes lead to accelerated geopolymerization, strengthen the structure of the geopolymer and improve the mechanical strength.

In all geopolymer mixtures, the broad bands present around $3350-3370 \mathrm{~cm}^{-1}$ are due to the stretching vibrations of $\mathrm{H}-\mathrm{O}-\mathrm{H}$ bonds, while those at $1640-1646 \mathrm{~cm}^{-1}$ are related to the bending vibration of $-\mathrm{OH}$ group of the products of the hydrated reaction associated with water. These bands do not exist in the unreacted FA and GGBS samples and indicate the geopolymerization reaction of alkaline activation products and water into geopolymer pastes [21].

\subsection{Thermal Analysis (DSC)}

Thermal analysis was used to evaluate the effect of GGBS content on the geopolymerisation reaction of the geopolymer paste mixtures using differential scanning calorimetry, $24 \mathrm{~h}$ after mixing the dry binder with the alkali activator solution.

Isothermal conduction data indicate that the activation process of the geopolymer paste was highly affected by the GGBS content of the total binder (Fig. 15). Thermal power is an indicator of the rate of the chemical reactions occurring between cementitious materials and water and admixtures. The main hydration peak (associated mainly with hydration reactions) is an indicator of setting and early strength development of the mixture $[48,49]$. The heat flow peaks were variable with different GGBS/binder ratio mixtures: the main thermal peaks of the geopolymer pastes were $0.0129 \mathrm{~mW} / \mathrm{mg}, 0.02 \mathrm{~mW} / \mathrm{mg}, 0.0414 \mathrm{~mW} / \mathrm{mg}$ and $0.034 \mathrm{~mW} / \mathrm{mg}$ for $20 \%, 30 \%, 40 \%$ and $50 \%$ GGBS to binder ratios. The initial peak related to the degree of the material particles' reaction and then the heat flow declined to a negative peak followed by small peaks corresponding to the formation of primary C-S-H [45]. In the case of the 305 mixture, the maximum peaks appeared earlier, possibly because loading the samples in the thermal analyser took a slightly longer time than the other mixtures. The time to reach the main peaks was reduced as the GGBS content was increased, although the time between the lower point and the first inflection point in the main maximum peak was increased from 58 to 145 minutes (by increasing GGBS from $20 \%$ to $50 \%$ of the total binder). Yu et al. [34] examined the effect of mixing GGBS and FA with Portland cement, and showed 
that GGBS can react quickly with $\mathrm{Ca}(\mathrm{OH})_{2}$ and generate a C-S-H gel, while the generation of this gel is delayed by the reaction of FA with portlandite. Therefore, increasing the dosage of slag strongly effects (accelerates) the hydration process of FA geopolymer composite, and the time to reach thermal peaks is subsequently reduced. Such a change reduces the setting time of the fresh geopolymer and improves early strength.

The weight loss of the geopolymer samples between the initial sample weight and final weight measurement after removing the samples from the furnace is presented in Table 6 . The results show that the weight loss increases from 15.5 to $20 \%$ by increasing GGBS content in the binder from $10-50 \%$. This loss of weight is an indication of liquid loss and the amount of gel formed during geopolymerization [46].

\section{Conclusions}

The present study investigated the mechanical and (micro) structural properties of 'user friendly' geopolymer mortar cured under ambient temperatures. These geopolymer mixes were produced using $12 \%$ potassium silicate with 1.25 molar ratio which leads to a noncorrosive cement free material. The geopolymer specimens were prepared by dry mixing FA and GGBS at five different ratios in order to optimize the mechanical properties, in a user friendly geopolymer system. Fresh geopolymer mortar properties were examined through workability and setting time, while the mechanical performance and physical and chemical characteristics of the hardened mortar were evaluated by compressive, direct tensile, flexural strength tests, SEM-EDS, porosity and FTIR analysis, and thermal heating. The following conclusions can be drawn from the results outlined here.

\section{Fresh geopolymer mortar characteristics}

- Increasing the GGBS content in the fly ash-based geopolymer mortar decreases the workability and accelerates the setting times (initial and final) and hardening.

\section{Hardened geopolymer mortar characteristics}

- Compressive strength was considerably affected by blend composition. Improvements in compressive strength have been observed by increasing the GGBS to total binder ratio in geopolymer mortar mixtures. Increasing GGBS content from $10 \%$ to $50 \%$ of the total binder increased the compressive strength from 18.45 to $48 \mathrm{MPa}$ at 28 days. 
- Hardened geopolymer materials can be produced without elevated heat curing. The 28day compressive strength of the specimens cured at room temperature is close to the strength of the respective specimens cured under heat treatment.

- The effect of GGBS content on the development of flexural and direct tensile strengths in ambient temperature cured geopolymer mortar was similar to that observed in the development of compressive strength. The $40 \mathrm{~S}$ mixture showed optimum results for flexural and tensile strength, at $6 \mathrm{MPa}$ and $3 \mathrm{MPa}$ respectively.

- The addition of GGBS lowered the total porosity of the FA and GGBS based geopolymer mixture.

- SEM/EDS analysis enabled assessment of microstructural evolution and reaction product formation in the geopolymer samples. The images show a less dense structure and non-reacted FA particles with low contents of GGBS. However, the compactness of the geopolymer matrix increased when GGBS content was increased.

- FTIR analysis allowed assessment of the degree of geopolymerization and the formation of reaction products. The addition of slag affected the structural reorganisation by increasing $\mathrm{C}-\mathrm{S}-\mathrm{H}$ gel formation and reducing the amount of aluminosilicate gel related to FA, which in turn accelerates geopolymerisation.

- Thermal analysis (DSC) showed that the addition of GGBS increased the heat flow in the samples and reduced the time to achieve the main thermal (reaction) peak due to accelerated formation of cementitious gels, leading to a reduction in the setting time.

The overall conclusion of the current study is that the examined 'user friendly' geopolymer mixes with increased GGBS content had considerably improved flexural and direct tensile strength, even without any heat curing treatment which makes the proposed method suitable for in situ applications. Further improvement of the mechanical properties of the examined mixes could be achieved by the addition of silica fume, fibres or nanoparticles [50]. 


\section{Acknowledgments}

The lead author gratefully acknowledges the Iraqi Ministry of Higher Education and Scientific Research-University of Basrah and Iraqi Cultural Attaché in London for the award of a Doctoral Scholarship.

\section{References}

[1] J. Xie, O. Kayali, Effect of initial water content and curing moisture conditions on the development of fly ash-based geopolymers in heat and ambient temperature, Construction and Building Materials (0) (2014).

[2] X.S. Shi, F.G. Collins, X.L. Zhao, Q.Y. Wang, Mechanical properties and microstructure analysis of fly ash geopolymeric recycled concrete, Journal of Hazardous Materials 237-238 (2012) 20-9.

[3] E. Gartner, Industrially interesting approaches to "low-CO2" cements, Cement and Concrete Research 34(9) (2004) 1489-1498.

[4] L.K. Turner, F.G. Collins, Carbon dioxide equivalent (CO2-e) emissions: A comparison between geopolymer and OPC cement concrete, Construction and Building Materials 43 (2013) 125-130.

[5] S. Akçaözoğlu, C.D. Atiş, Effect of Granulated Blast Furnace Slag and fly ash addition on the strength properties of lightweight mortars containing waste PET aggregates, Construction and Building Materials 25(10) (2011) 4052-4058.

[6] A. Islam, U.J. Alengaram, M.Z. Jumaat, I.I. Bashar, The development of compressive strength of ground granulated blast furnace slag-palm oil fuel ash-fly ash based geopolymer mortar, Materials and Design 56(0) (2014) 833-841.

[7] M. Komljenović, Z. Baščarević, V. Bradić, Mechanical and microstructural properties of alkaliactivated fly ash geopolymers, Journal of Hazardous Materials 181(1-3) (2010) 35-42.

[8] I. Ismail, S.A. Bernal, J.L. Provis, R. San Nicolas, S. Hamdan, J.S.J. van Deventer, Modification of phase evolution in alkali-activated blast furnace slag by the incorporation of fly ash, Cement and Concrete Composites 45 (2014) 125-135.

[9] P.S. Deb, P. Nath, P.K. Sarker, The effects of ground granulated blast-furnace slag blending with fly ash and activator content on the workability and strength properties of geopolymer concrete cured at ambient temperature, Materials and Design 62(0) (2014) 32-39.

[10] G.S. Ryu, Y.B. Lee, K.T. Koh, Y.S. Chung, The mechanical properties of fly ash-based geopolymer concrete with alkaline activators, Construction and Building Materials 47 (2013) 409-418.

[11] P. Duxson, et al. , Geopolymer technology: the current state of the art., Journal of Materials Science (2007) 2917-2933.

[12] B. Joseph, G. Mathew, Influence of aggregate content on the behavior of fly ash based geopolymer concrete, Scientia Iranica 19(5) (2012) 1188-1194.

[13] A.-O. S., Durability of concrete incorporating GGBS activated by waterglass., Construction and Building Material 22 (2008) 2059.

[14] J. Davidovits, Geopolymer Chemistry and Applications, 3 ed., Geopolymer Institute, 20112011.

[15] P.J. Lloyd RR, van Deventer JSJ., Microscopy and microanalysis of inorganic polymer cements. 1: remnant fly ash particles, Journal of Material Science 44(2) (2009) 608-19.

[16] M. Chi, R. Huang, Binding mechanism and properties of alkali-activated fly ash/slag mortars, Construction and Building Materials 40 (2013) 291-298.

[17] N. Marjanović, M. Komljenović, Z. Baščarević, V. Nikolić, R. Petrović, Physical-mechanical and microstructural properties of alkali-activated fly ash-blast furnace slag blends, Ceramics International 41(1, Part B) (2015) 1421-1435.

[18] S.A. Barbhuiya, J.K. Gbagbo, M.I. Russell, P.A.M. Basheer, Properties of fly ash concrete modified with hydrated lime and silica fume, Construction and Building Materials 23(10) (2009) 3233-3239. 
[19] M. Rowles, B. O'Connor, Chemical optimisation of the compressive strength of aluminosilicate geopolymers synthesised by sodium silicate activation of metakaolinite, Journal of Materials Chemistry 13(5) (2003) 1161-1165.

[20] T. Bakharev, Geopolymeric materials prepared using Class F fly ash and elevated temperature curing, Cement and Concrete Research 35(6) (2005) 1224-1232.

[21] K. Somna, C. Jaturapitakkul, P. Kajitvichyanukul, P. Chindaprasirt, NaOH-activated ground fly ash geopolymer cured at ambient temperature, Fuel 90(6) (2011) 2118-2124.

[22] J.G.S. van Jaarsveld, J.S.J. van Deventer, G.C. Lukey, The effect of composition and temperature on the properties of fly ash- and kaolinite-based geopolymers, Chemical Engineering Journal 89(1-3) (2002) 63-73.

[23] N.K. Lee, H.K. Lee, Setting and mechanical properties of alkali-activated fly ash/slag concrete manufactured at room temperature, Construction and Building Materials 47(0) (2013) 1201-1209.

[24] J.G. Jang, N.K. Lee, H.K. Lee, Fresh and hardened properties of alkali-activated fly ash/slag pastes with superplasticizers, Construction and Building Materials 50(0) (2014) 169-176.

[25] P. Nath, P.K. Sarker, Effect of GGBFS on setting, workability and early strength properties of fly ash geopolymer concrete cured in ambient condition, Construction and Building Materials 66(0) (2014) 163-171.

[26] J. Davidovits, M.Izquierdo, X.Querol, D. Antennuci, H. Nugteren, V. Butselaar-Orthlieb, C., Fernández-Pereira, Y. Luna, The European Research Project GEOASH: Geopolymer Cement Based On European Coal Fly Ashes, Technical Paper \#22, Geopolymer Institute Library (2014).

[27] BS EN 450-1: Fly ash for concrete. Definition, specifications and conformity criteria,31 August 2012.

[28] EN 934-2:2009, Admixtures for concrete, mortar and grout - Part 2: Concrete admixtures Definitions, requirements, conformity, marking and labelling, 2009.

[29] Wallah, S.E. and Rangan, B.V. (2006), Low-Calcium Fly Ash-Based Geopolymer Concrete: LongTerm Properties, Research Report GC2, Faculty of Engineering, Curtin University of Technology, Perth (2006).

[30] BS EN 480-2, Admixtures for concrete, mortar and grout. Test methods., Determination of setting time, 2006.

[31] BS-EN-1015-3, Methods of test for mortar for masonry - Part 3: Determination of consistence of fresh mortar (by flow table). British Standards Institution-BSI and CEN European Committee for Standardization, 2007.

[32] ASTM C 1437-07, Standard test methods for flow of hydraulic cement mortar. West Conshohocken, PA: ASTM International, 2008.

[33] B. Nematollahi, J. Sanjayan, Effect of different superplasticizers and activator combinations on workability and strength of fly ash based geopolymer, Materials and Design 57(0) (2014) 667-672.

[34] R. Yu, P. Spiesz, H.J.H. Brouwers, Development of an eco-friendly Ultra-High Performance Concrete (UHPC) with efficient cement and mineral admixtures uses, Cement and Concrete Composites 55(0) (2015) 383-394.

[35] ASTM C109/C109M, Standard test method for compressive strength of hydraulic cement mortars (using $50 \mathrm{~mm}$ [2 in.] cube specimens). United States: ASTM Standards, 2007.

[36] ASTM C293-02, Standard Test Method for Flexural Strength of Concrete (Using Simple Beam With Center-Point Loading), ASTM International, West Conshohocken, PA, 2002.

[37] AASHTO T132, Standard Method of Test for Tensile Strength of Hydraulic Cement Mortars, In American Association of State Highway and Transportation Officials, Standard Specifications for Transportation Materials and Methods of Sampling and Testing, Washington, DC, 2000.

[38] T. Gonen, S. Yazicioglu, The influence of compaction pores on sorptivity and carbonation of concrete, Construction and Building Materials 21(5) (2007) 1040-1045. 
[39] O. Keleştemur, B. Demirel, Corrosion behavior of reinforcing steel embedded in concrete produced with finely ground pumice and silica fume, Construction and Building Materials 24(10) (2010) 1898-1905.

[40] W. Shen, Y. Wang, T. Zhang, M. Zhou, J. Li, X. Cui, Magnesia modification of alkali-activated slag fly ash cement, Journal of Wuhan University of Technology-Mater. Sci. Ed. 26(1) (2011) 121-125.

[41] W.K. Part, M. Ramli, C.B. Cheah, An overview on the influence of various factors on the properties of geopolymer concrete derived from industrial by-products, Construction and Building Materials 77(0) (2015) 370-395.

[42] G. Görhan, G. Kürklü, The influence of the $\mathrm{NaOH}$ solution on the properties of the fly ash-based geopolymer mortar cured at different temperatures, Composites Part B: Engineering 58(0) (2014) 371377.

[43] A.M. Rashad, A comprehensive overview about the effect of nano-SiO2 on some properties of traditional cementitious materials and alkali-activated fly ash, Construction and Building Materials 52(0) (2014) 437-464.

[44] M. Izquierdo, X. Querol, J. Davidovits, D. Antenucci, H. Nugteren, C. Fernández-Pereira, Coal fly ash-slag-based geopolymers: Microstructure and metal leaching, Journal of Hazardous Materials 166(1) (2009) 561-566.

[45] S.K. Nath, S. Kumar, Influence of iron making slags on strength and microstructure of fly ash geopolymer, Construction and Building Materials 38(0) (2013) 924-930.

[46] S.H. Guo X, Chen L, Dick WA. , Alkali-activated complex binders from Class C fly ash and Cacontaining admixtures, Journal Hazard Material 173(1-3) (2010) 480-6.

[47] A.M. Rashad, A comprehensive overview about the influence of different admixtures and additives on the properties of alkali-activated fly ash, Materials and Design 53(0) (2014) 1005-1025.

[48] N.K. Lee, H.K. Lee, Reactivity and reaction products of alkali-activated, fly ash/slag paste, Construction and Building Materials 81(0) (2015) 303-312.

[49] ASTM C 1679. Practice for measuring hydration kinetics of hydraulic cementitious mixtures using isothermal calorimetry. Annual Book of ASTM Standards, 2008.

[50] M. Saafi, K. Andrew, P.L. Tang, D. McGhon, S. Taylor, M. Rahman, S. Yang, X. Zhou, Multifunctional properties of carbon nanotube/fly ash geopolymeric nanocomposites, Construction and Building Materials 49 (2013) 46-55. 


\section{List of Tables}

Table 1. Chemical compositions of FA, GGBS and Silica Sand.

\begin{tabular}{cccc}
\hline Chemical compositions (\%) & $\begin{array}{c}\text { Fly } \\
\text { ash }\end{array}$ & Slag & Silica Sand \\
\hline Silicon Dioxide, $\mathrm{SiO}_{2}$ & 59 & 35 & 99.73 \\
Aluminium Oxide, $\mathrm{Al}_{2} \mathrm{O}_{3}$ & 23 & 12 & 0.1 \\
Calcium Oxide, $\mathrm{CaO}$ & 2.38 & 40 & -- \\
Ferric Oxide, $\mathrm{Fe}_{2} \mathrm{O}_{3}$ & 8.8 & 0.2 & 0.051 \\
Sulphur Trioxide, $\mathrm{SO}_{3}$ & 0.27 & -- & -- \\
Sodium Oxide, $\mathrm{Na}_{2} \mathrm{O}$ & 0.74 & -- & $<0.05$ \\
Potassium Oxide, $\mathrm{K}_{2} \mathrm{O}$ & 2.81 & -- & 0.01 \\
Magnesium Oxide, $\mathrm{MgO}$ & 1.39 & 10 & -- \\
Loss on ignition, $\mathrm{LOI}$ & 6.7 & -- & 0.09 \\
\hline
\end{tabular}

Table 2 Mixture compositions of fly ash / slag based geopolymer mortar used in the present study.

\begin{tabular}{cccccc}
\hline $\begin{array}{c}\text { Mixture } \\
\text { ID }\end{array}$ & $\begin{array}{c}\text { Fly } \\
\text { Ash }\end{array}$ & Slag & $\begin{array}{c}\mathrm{K}_{2} \mathrm{SiO}_{3} / \text { binder } \\
(\mathrm{k} / \mathrm{b})\end{array}$ & Water /binder $(\mathrm{w} / \mathrm{b})$ & $\begin{array}{c}\text { Polycarboxylate /binder } \\
(\mathrm{p} / \mathrm{b})\end{array}$ \\
\hline 10S & 0.9 & 0.1 & 0.12 & 0.25 & 0.01 \\
$20 \mathrm{~S}$ & 0.8 & 0.2 & 0.12 & 0.25 & 0.01 \\
$30 \mathrm{~S}$ & 0.7 & 0.3 & 0.12 & 0.25 & 0.01 \\
$40 \mathrm{~S}$ & 0.6 & 0.4 & 0.12 & 0.25 & 0.01 \\
$50 \mathrm{~S}$ & 0.5 & 0.5 & 0.12 & 0.25 & 0.01 \\
\hline
\end{tabular}

Table 3. Number and type of specimens for each mixture. See Table 3 for mixture ID.

\begin{tabular}{ccccc}
\hline N.O.S & Type & $\begin{array}{c}\text { Dimensions } \\
(\mathrm{mm})\end{array}$ & Experimental test & Mixture \\
\hline 12 & Cubic & $50 \times 50 \times 50$ & Compression & 10S, 20S, 30S, 40S \& 50S \\
9 & Prismatic & $75 \times 75 \times 285$ & 3-Point-bending & 10S, 20S, 30S \& 40S \\
9 & Dog bone & $25 \times 25 \times 76$ & Direct tensile & 10S, 20S, 30S \& 40S \\
& shape & & Porosity & 10S, 20S, 30S \& 40S \\
\hline
\end{tabular}


Table 4. Particle size analysis by Malvern mastersizer 2000.

\begin{tabular}{ccc}
\hline & Fly ash & Slag \\
\hline $\mathbf{d}(\mathbf{0 . 1})$ & 1.8 & 1.85 \\
$\mathbf{d}(\mathbf{0 . 5})$ & 10.6 & 14.3 \\
$\mathbf{d}(\mathbf{0 . 9})$ & 44.4 & 45 \\
\hline
\end{tabular}

Table 5. Atomic weight components (wt. \%) slag and fly ash.

\begin{tabular}{ccc}
\hline Element & Slag & Fly ash \\
\hline $\mathrm{Si}$ & 12.3 & 22.5 \\
$\mathrm{Al}$ & 5.1 & 12.9 \\
$\mathrm{O}$ & 38 & 57.93 \\
$\mathrm{Na}$ & 0.3 & 0.5 \\
$\mathrm{Mg}$ & 3.4 & 0.9 \\
$\mathrm{Ca}$ & 37.7 & 1.0 \\
$\mathrm{Fe}$ & 0.4 & 4.7 \\
\hline
\end{tabular}

Table 6. Weight loss and time of heat flow peaks.

\begin{tabular}{cccccccc}
\hline \multirow{2}{*}{$\begin{array}{c}\text { Mix } \\
\text { no. }\end{array}$} & \multirow{2}{*}{$\begin{array}{c}\text { Slag } \\
(\%)\end{array}$} & \multicolumn{2}{c}{ Heat flow $(\mathrm{mW} / \mathrm{mg})$} & \multicolumn{3}{c}{ Time (min) } \\
\hline & & loss $(\%)$ & $\begin{array}{c}\text { Max } \\
\text { peak }\end{array}$ & $\begin{array}{c}\text { Min } \\
\text { peak }\end{array}$ & $\begin{array}{c}\text { Max } \\
\text { peak }\end{array}$ & $\begin{array}{c}\text { Min } \\
\text { peak }\end{array}$ & Equilibrium \\
\hline 1 & 10 & 13.69 & 0.04191 & 0.015 & 14 & 72 & 923 \\
2 & 20 & 15.52 & 0.0129 & 0.0117 & 29 & 87 & 995 \\
3 & 30 & 19.08 & 0.02 & 0.016 & 0 & 288 & 620 \\
4 & 40 & 20.09 & 0.04147 & 0.0173 & 14 & 159 & 634 \\
5 & 50 & --- & 0.034 & 0.00943 & 14 & 159 & 678 \\
\hline
\end{tabular}




\section{List of figures' captions}

Fig.1. Layout of the specimens employed (a) for the three-point bending test and ( $b$ ) for direct tensile test. (c) Shows the direct tensile test setup.

Fig.2. SEM images of (a) fly ash (b) GGBS.

Fig.3. Summary results from laser diffraction particle size analysis.

Fig.4. Effect of slag content on the setting time of geopolymer mortar.

Fig. 5. Effect of differing slag contents on the workability (determined via relative slump testing) of the fly ash / slag based geopolymer paste.

Fig.6. Effect of slag content on the compressive strength of geopolymer mortar samples cured at ambient temperature.

Fig. 7. Effect of curing temperature on the compressive strength of $50 \mathrm{~S}$ geopolymer mortar.

Fig. 8. Effect of slag content on the tensile strength of geopolymer mortar samples cured at ambient temperature.

Fig. 9. Effect of slag content on the ultimate flexural strength of geopolymer mortar samples cured at ambient temperature.

Fig. 10. Porosity results for different mixing ratios of geopolymer mortar.

Fig. 11. EDS Analysis of (a) fly ash (left) and (b) slag (right).

Fig. 12. SEM analysis of a $10 \%$ slag sample after (a) 7 days curing, $x 3,000$ magnification (b) 7 days curing, $\times 10,000$ magnification (c) 28 days curing, x3, 000 magnification (d) 28 days curing, $x 10,000$ magnification and (e) 28 days curing, $\times 20,000$ magnification.

Fig. 13. SEM analysis of a $40 \%$ slag sample after (a) 7 days curing, $x 3,000$ magnification (b) 7 days curing, x10, 000 magnification (c) 28days curing, x3, 000 magnification (d) 28 days curing, x10, 000 magnification and (e) 28 days curing, $\times 20,000$ magnification.

Fig. 14. FTIR analysis of (a) fly ash and slag, and (b) geopolymer paste (10S, 20S, 30S and $40 \mathrm{~S}$ samples).

Fig. 15. Heat flow vs. time curves for various slag/ binder geopolymer mixes, obtained using DSC. All samples contain identical amounts of binder and alkaline liquid. 


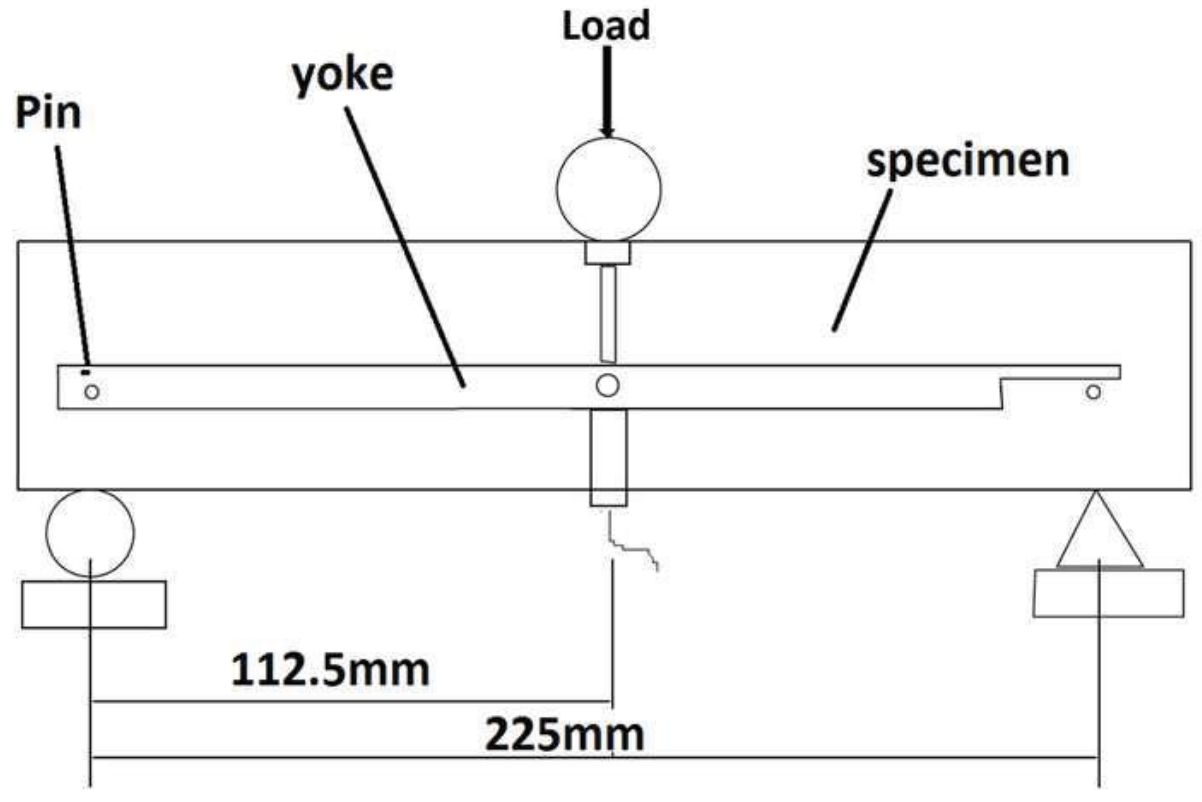

Fig. 1a

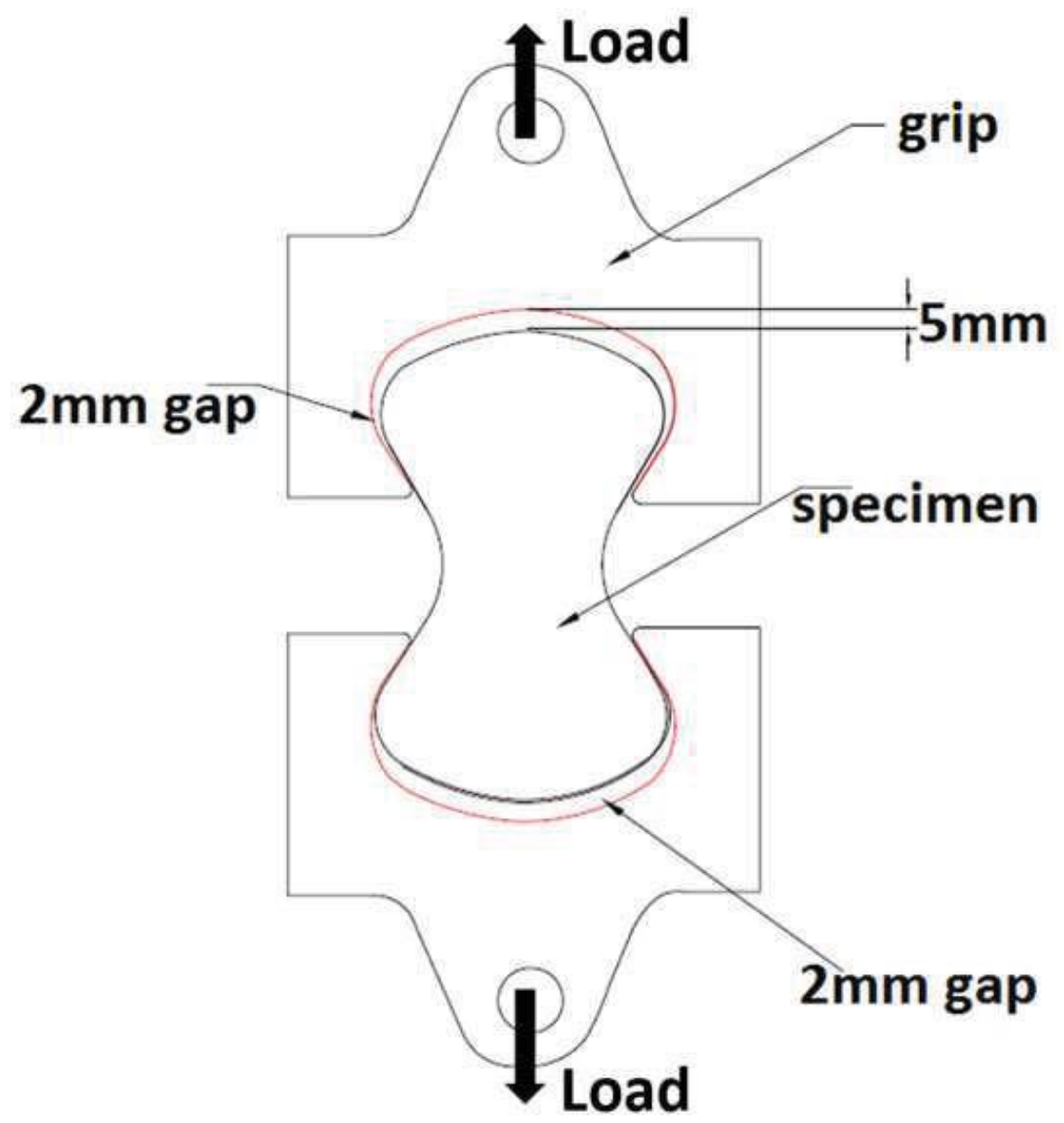

Fig. 1b 


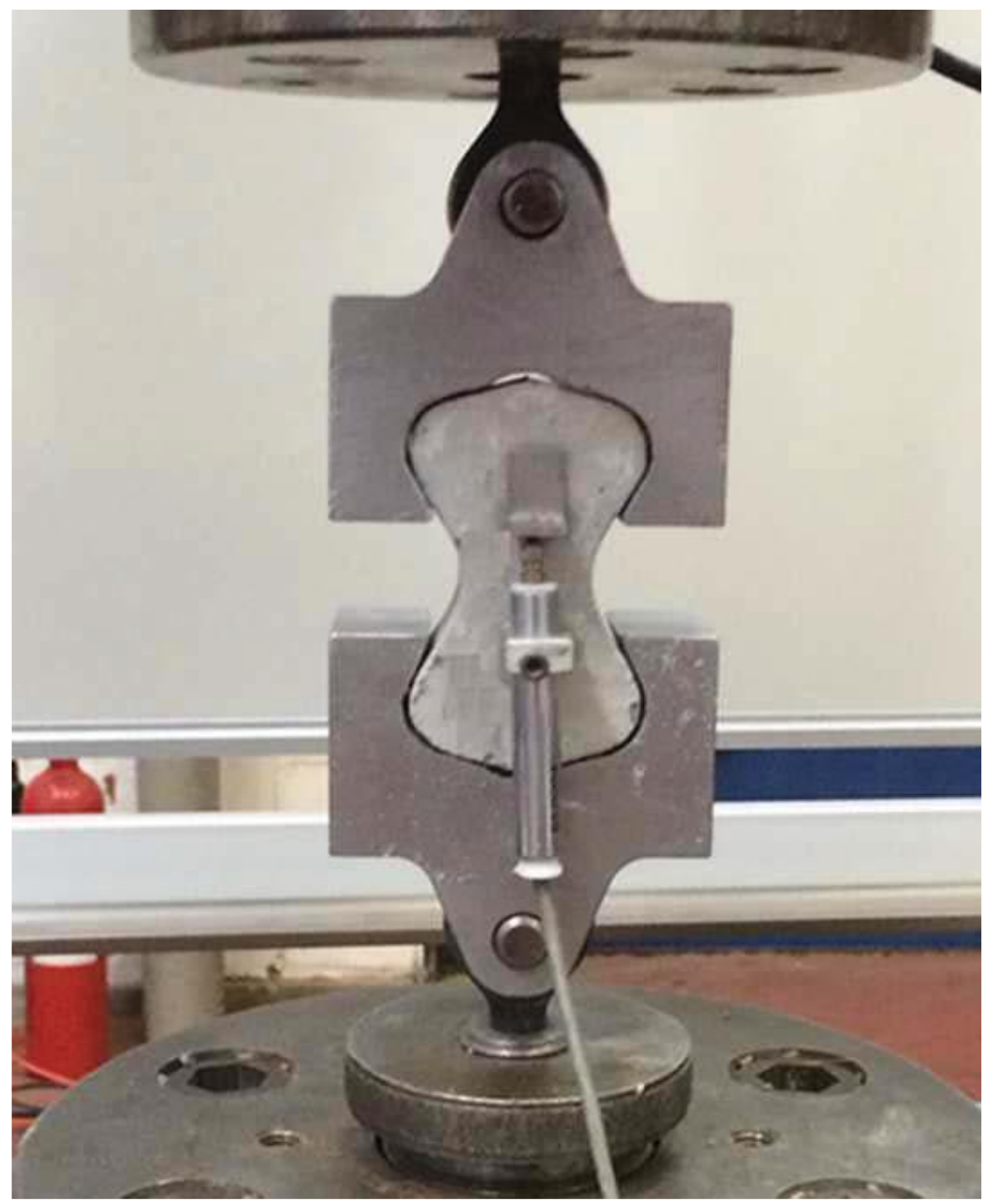

Fig. 1c

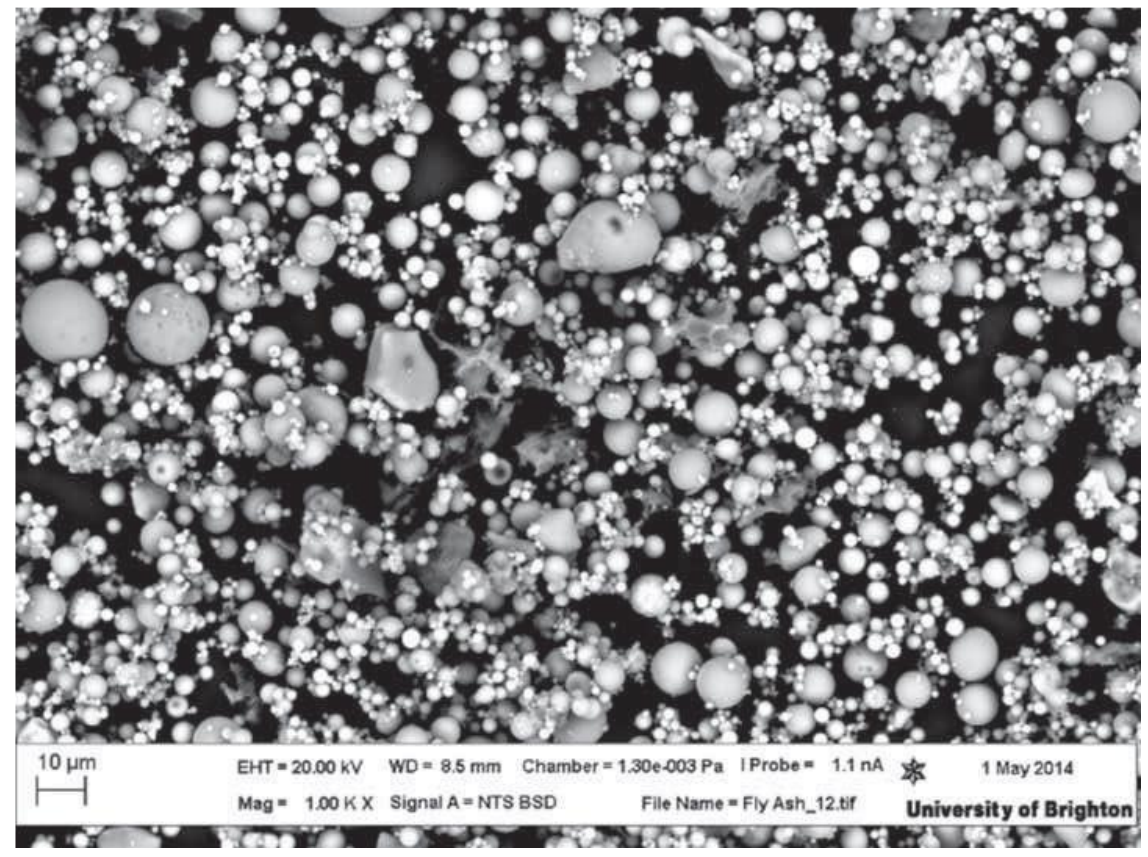

Fig. 2a 


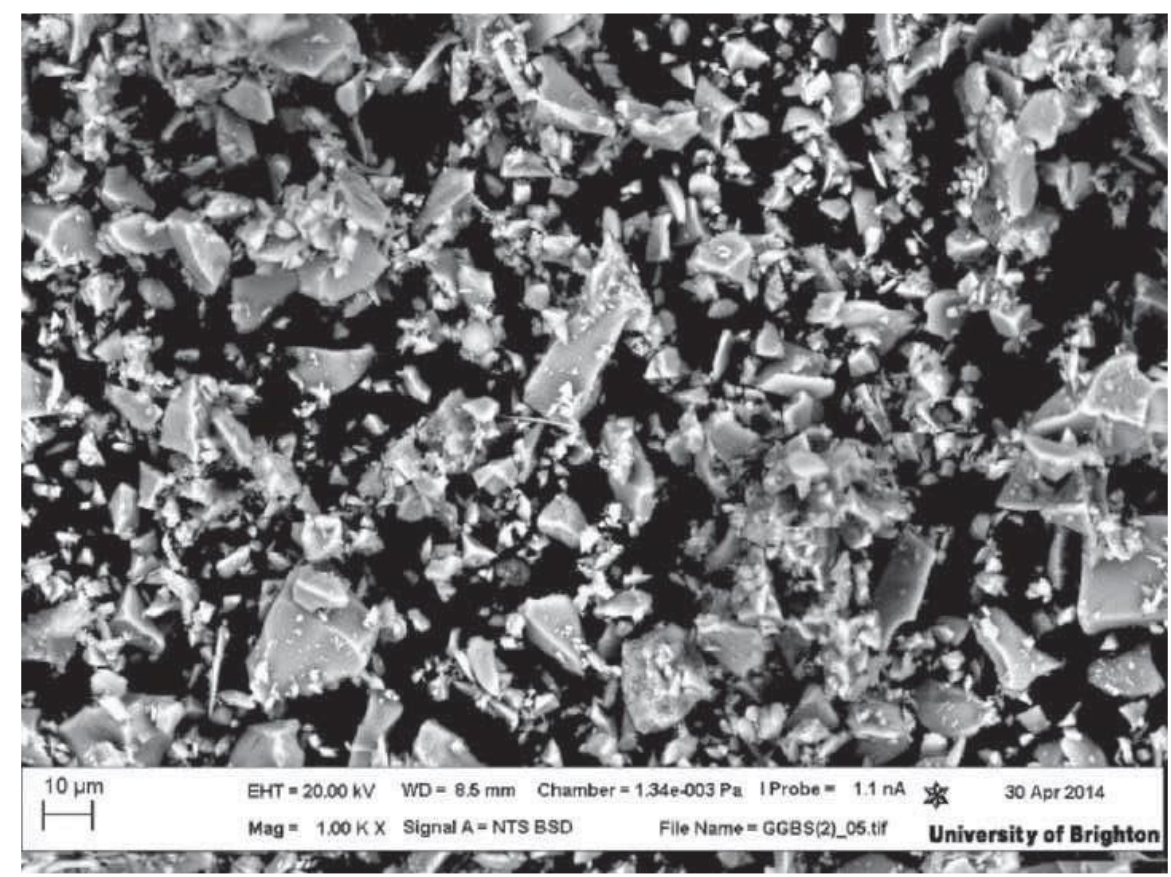

Fig. 2b

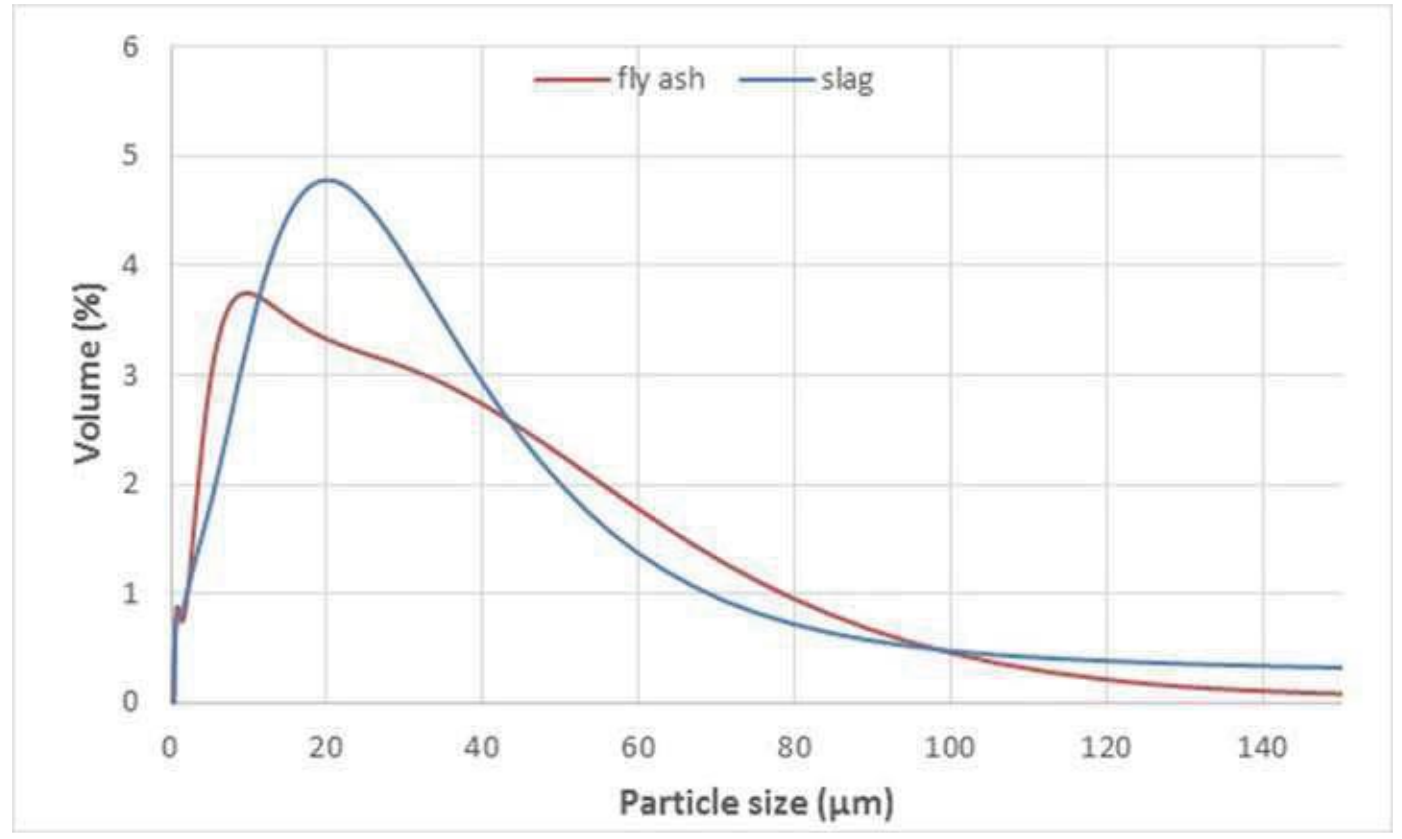

Fig. 3 


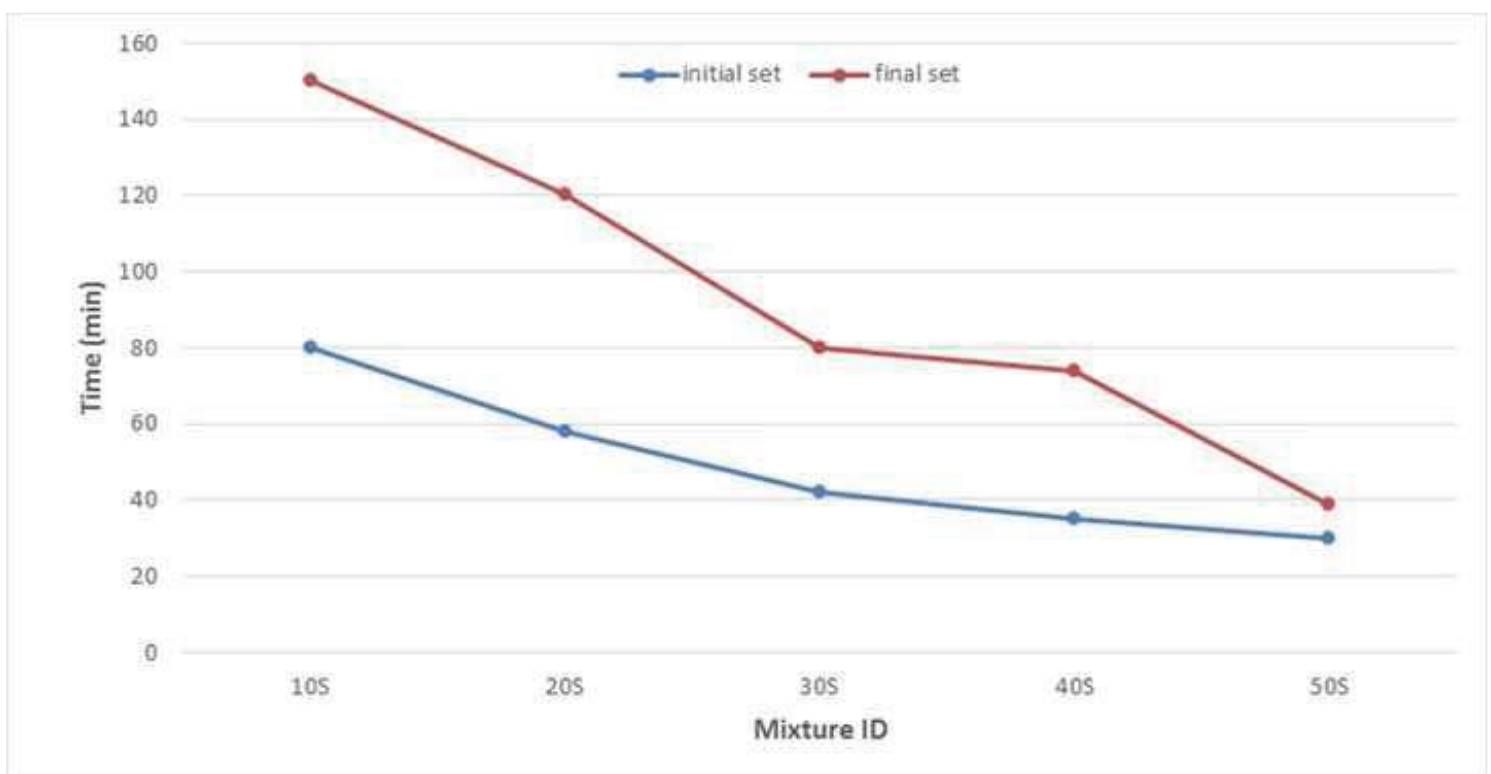

Fig. 4

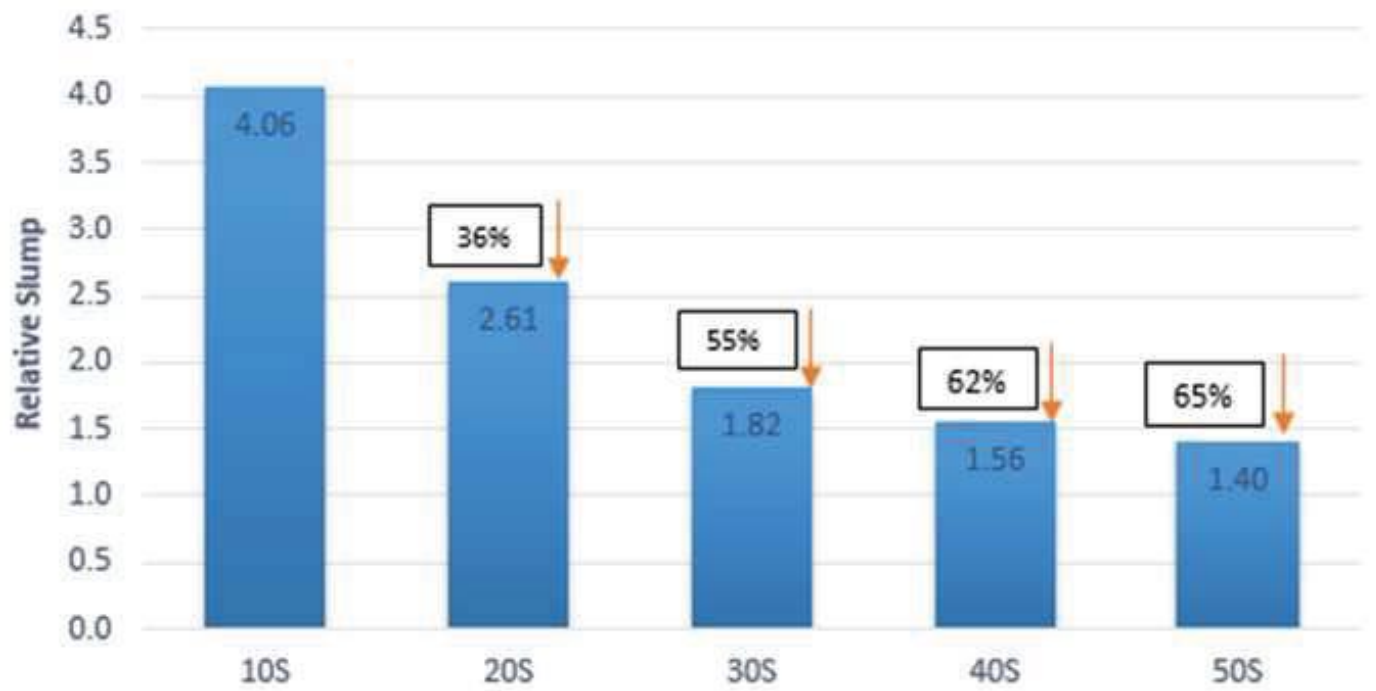

Fig. 5 


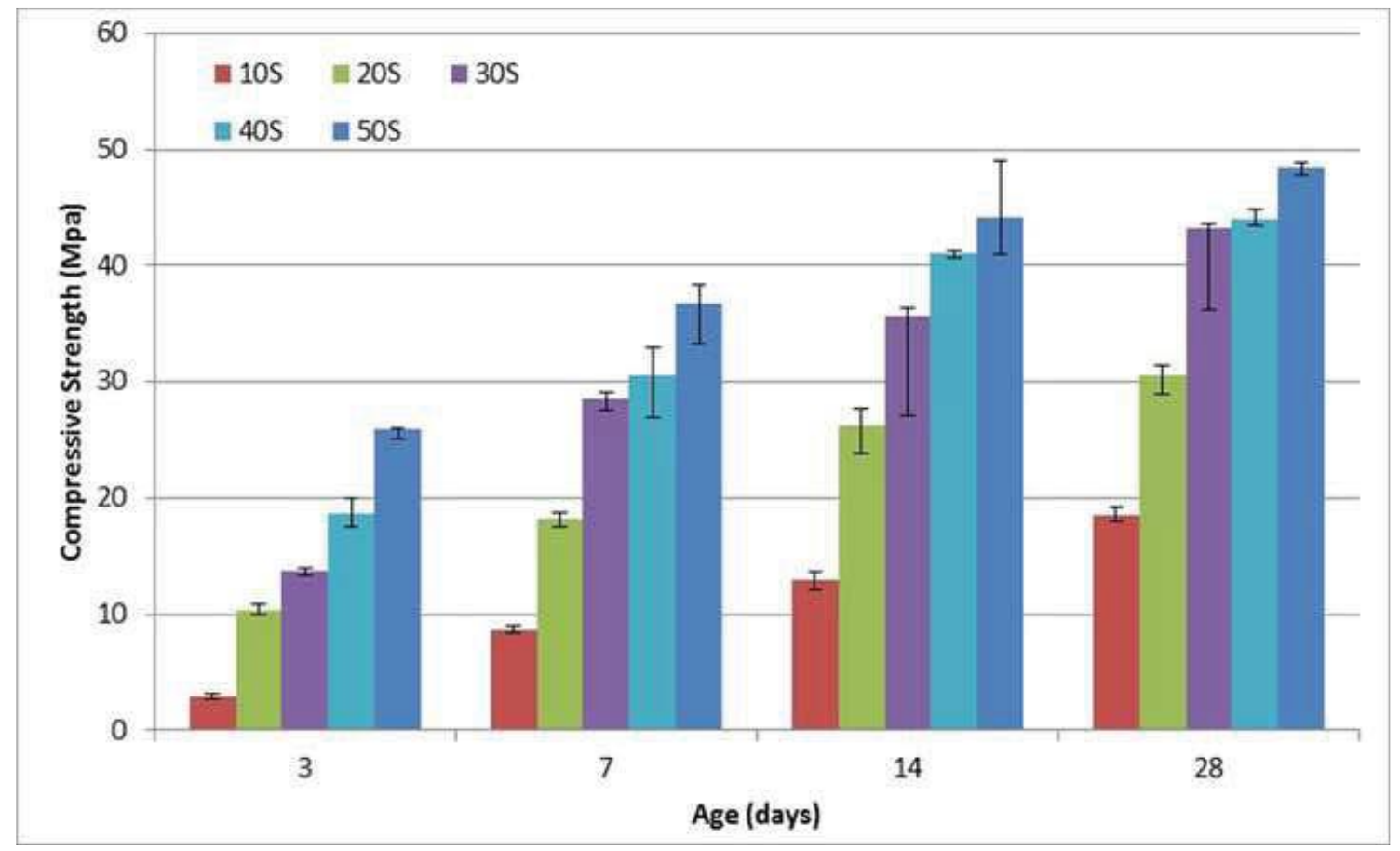

Fig.6

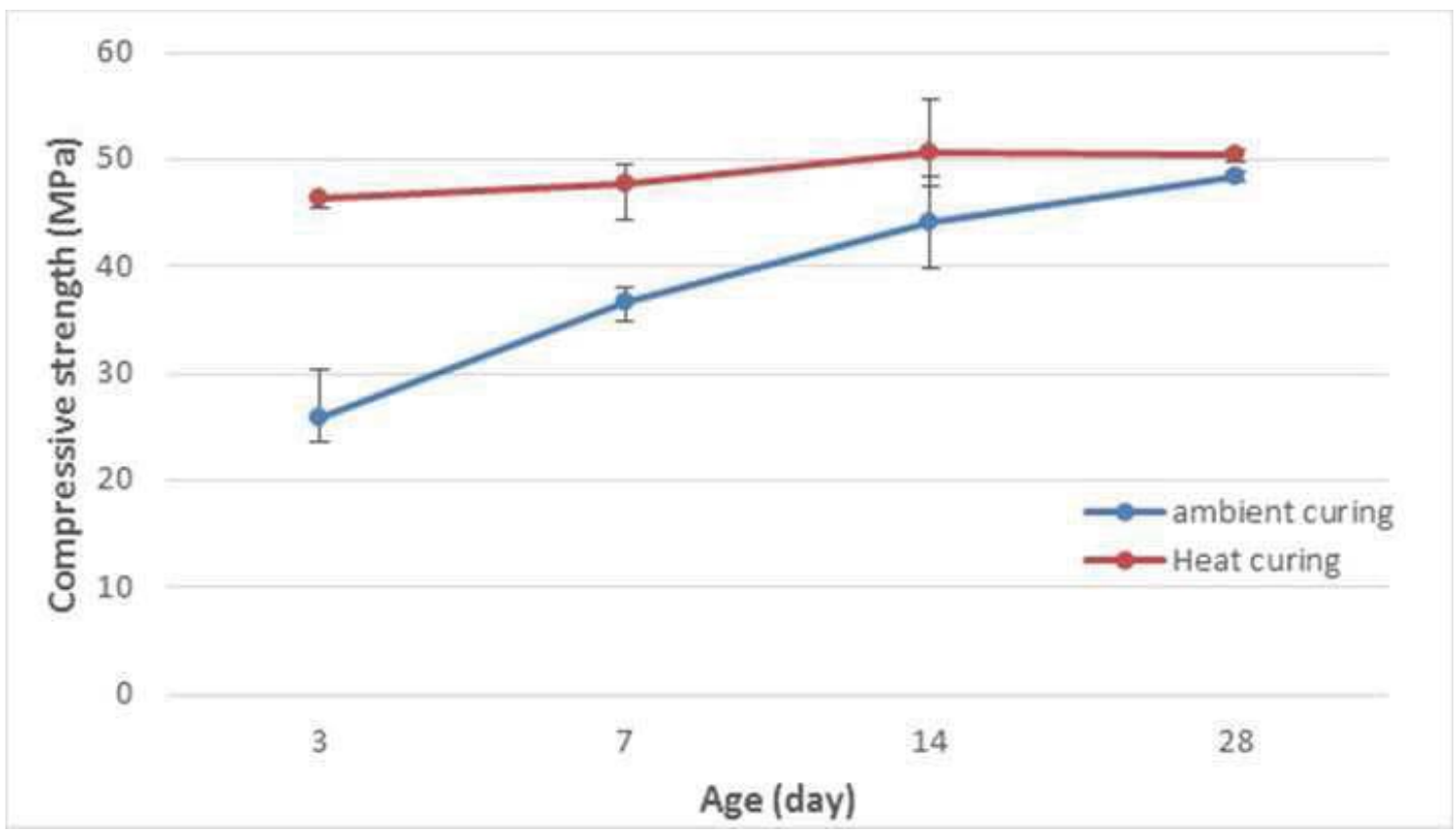

Fig. 7 


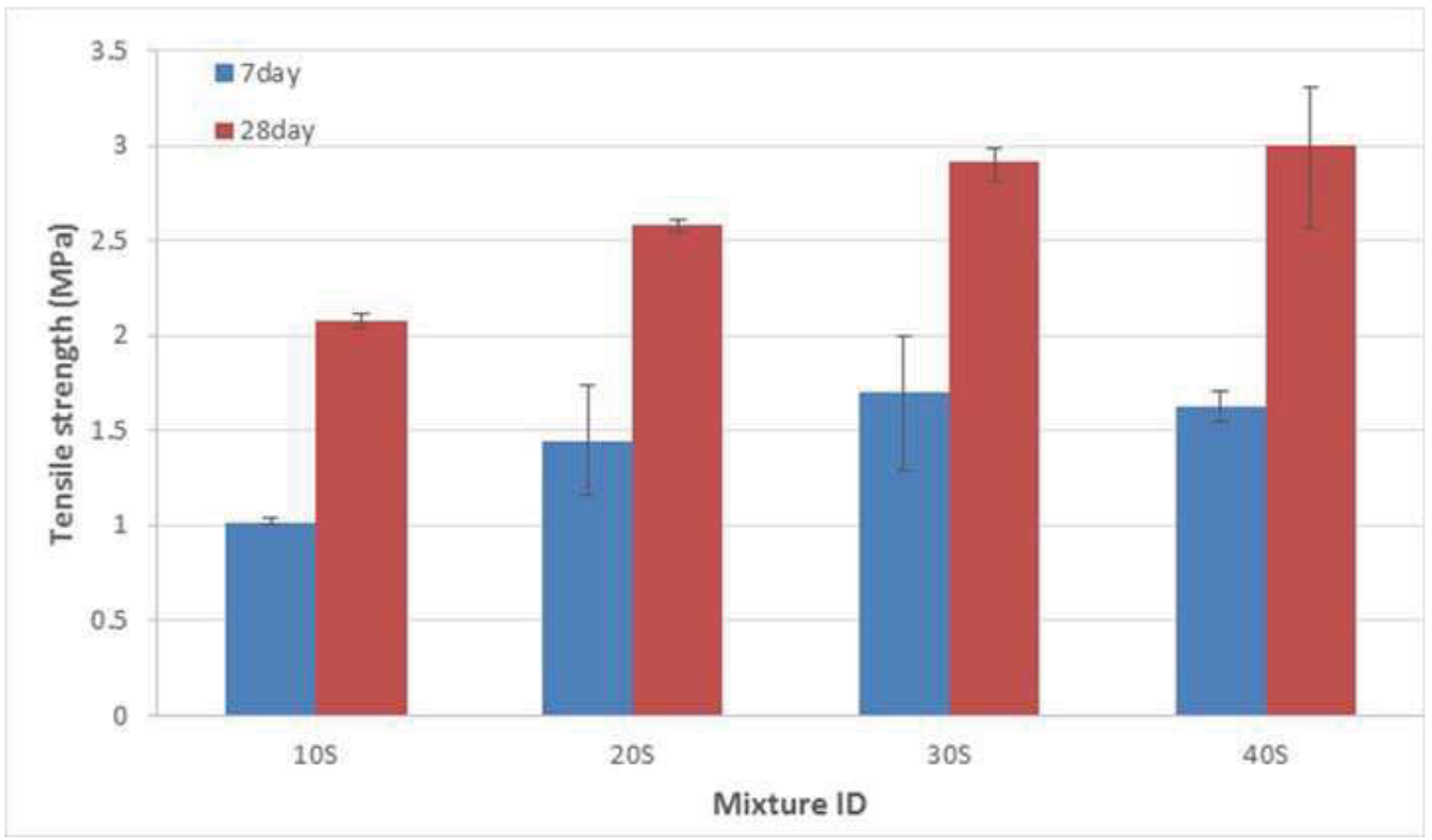

Fig. 8

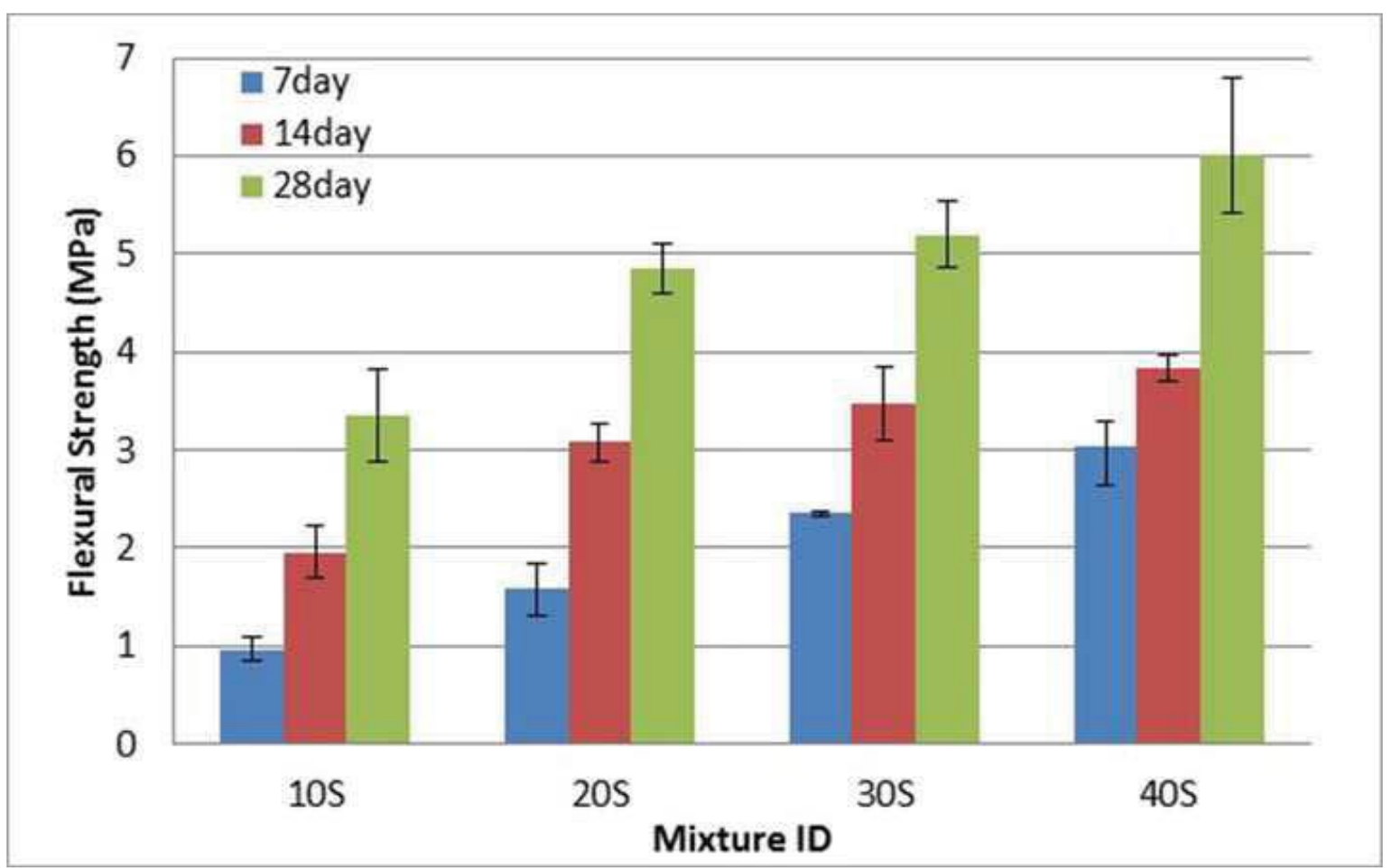

Fig. 9 


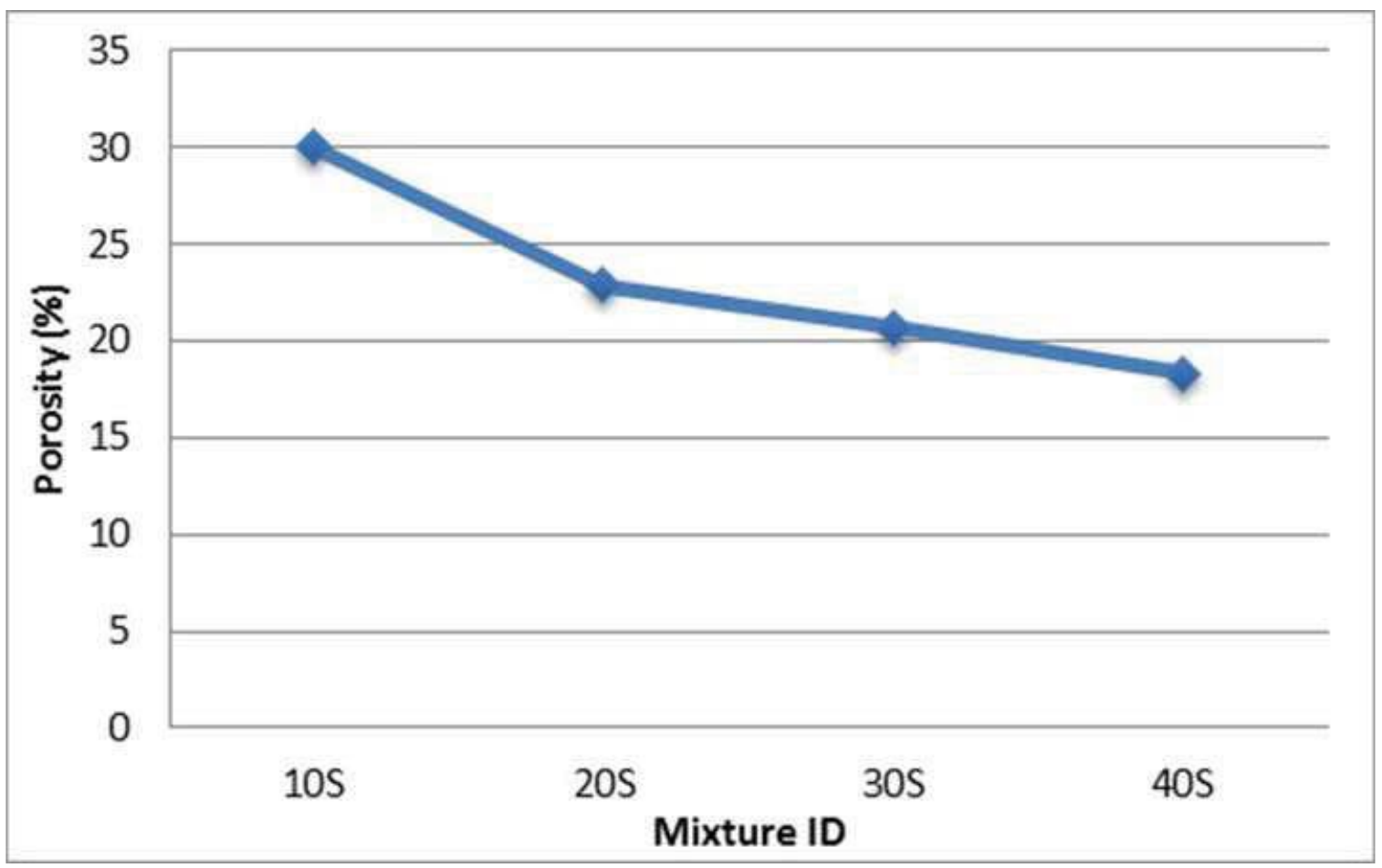

Fig. 10 

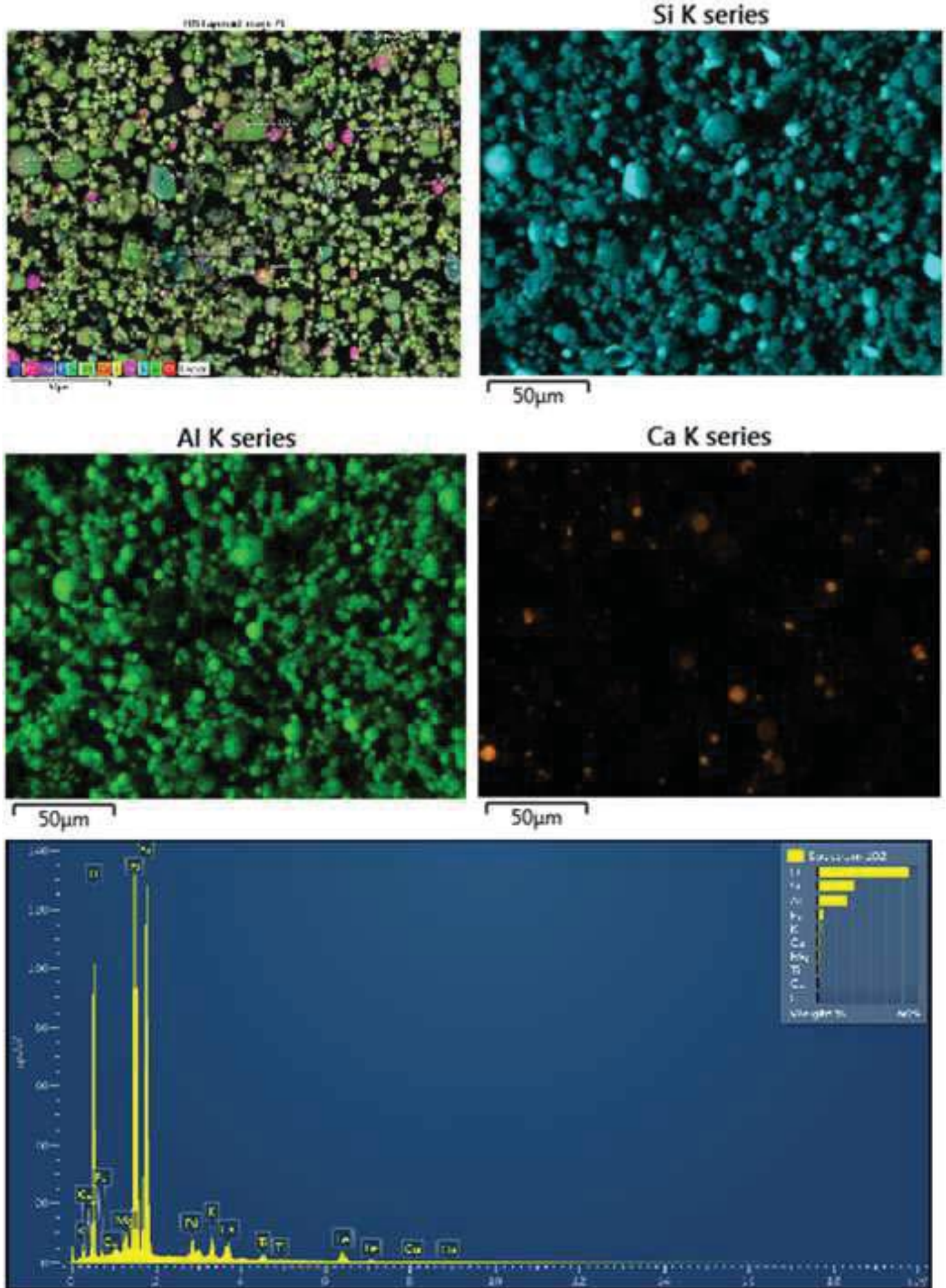

Fig. 11a 

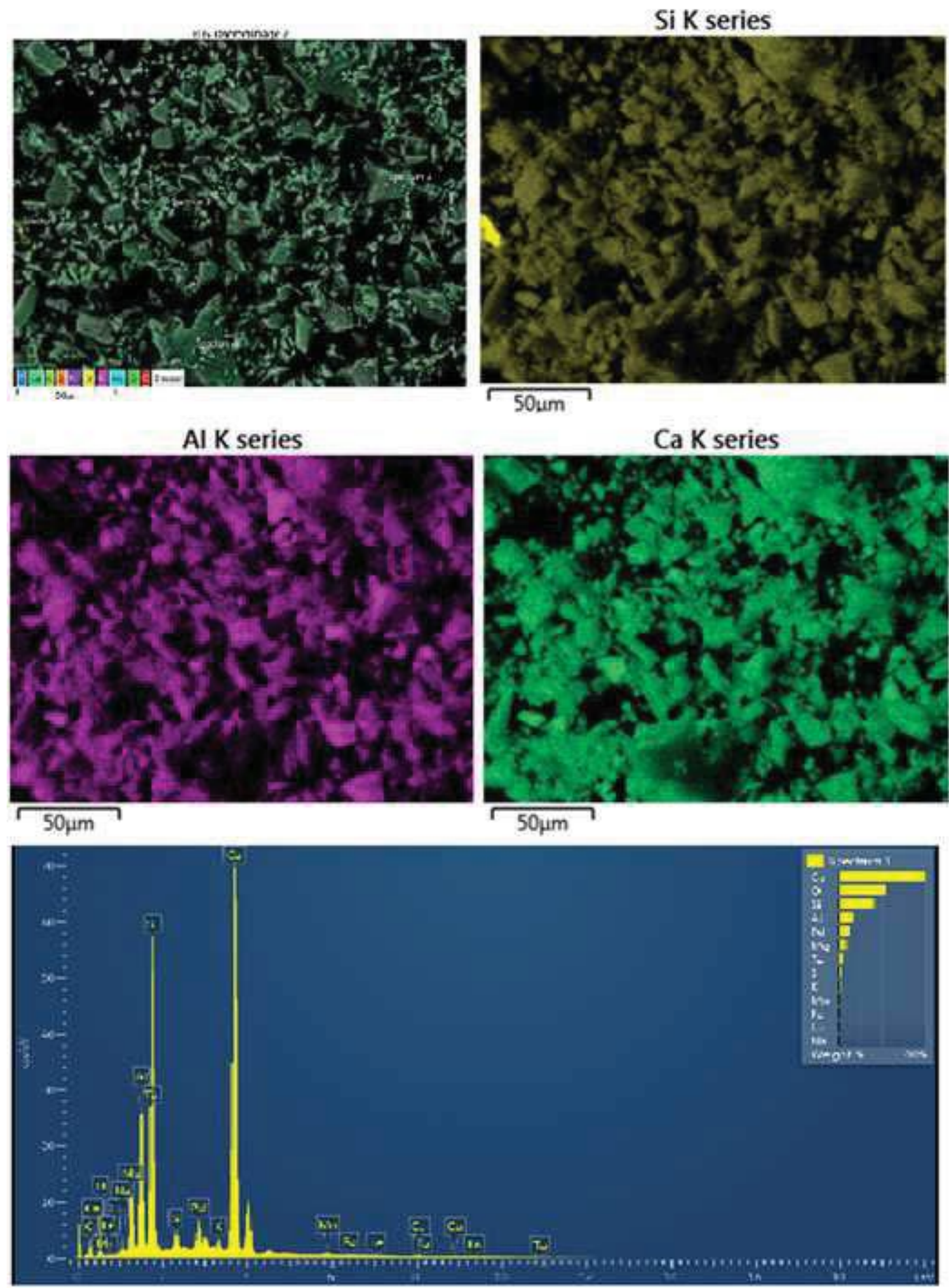

Fig. $11 \mathrm{~b}$ 


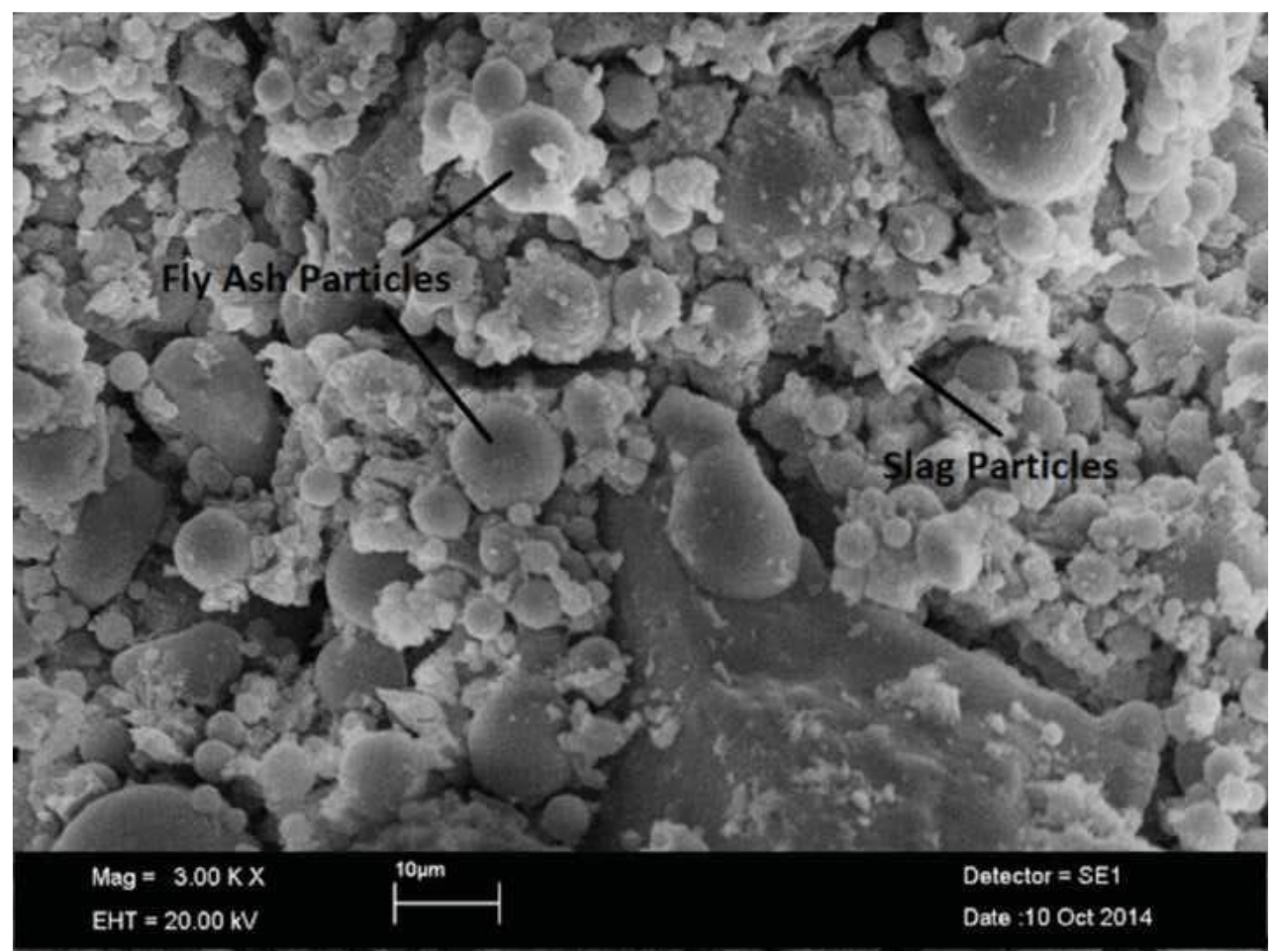

Fig. 12a

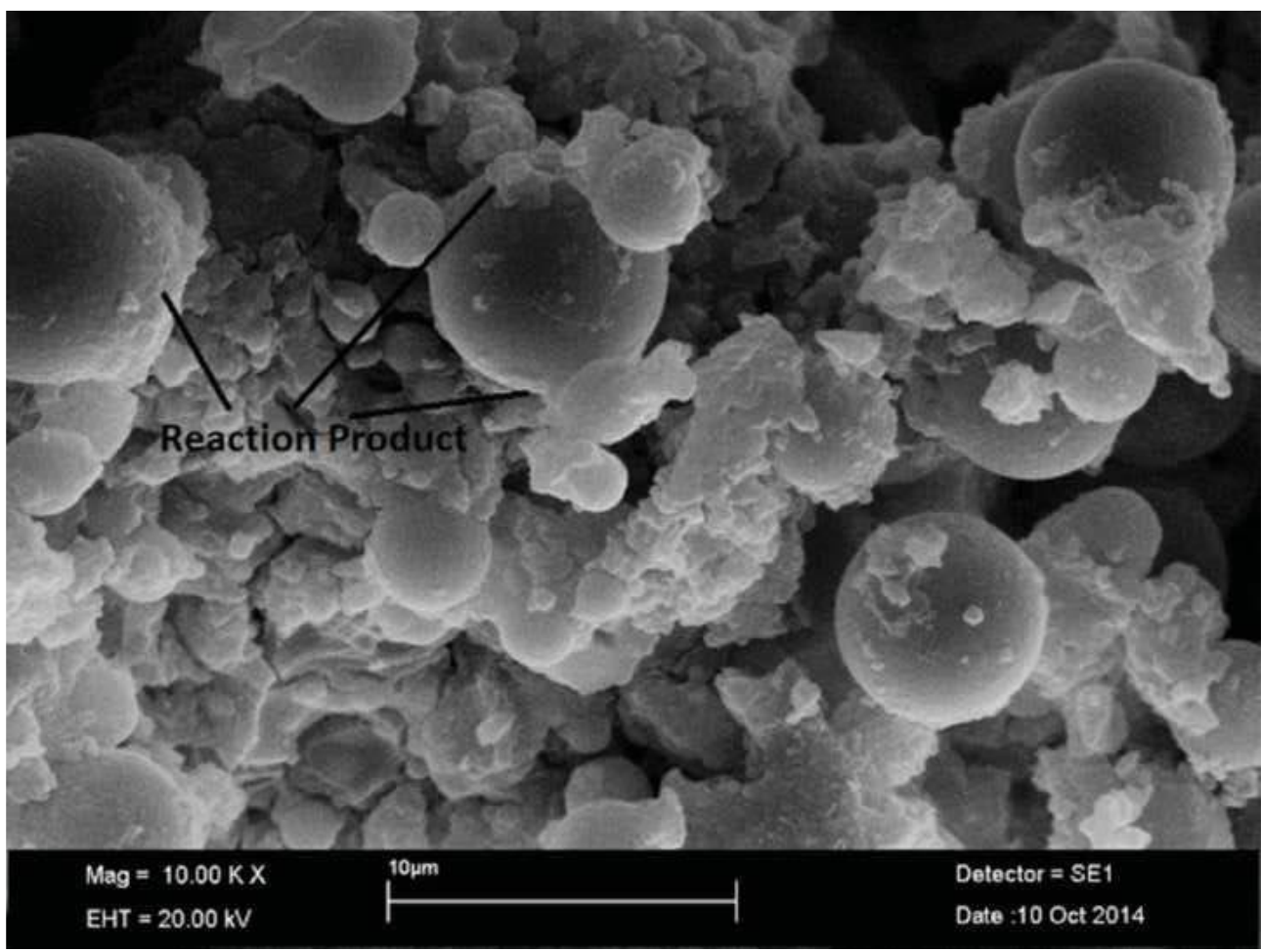

Fig. 12b 


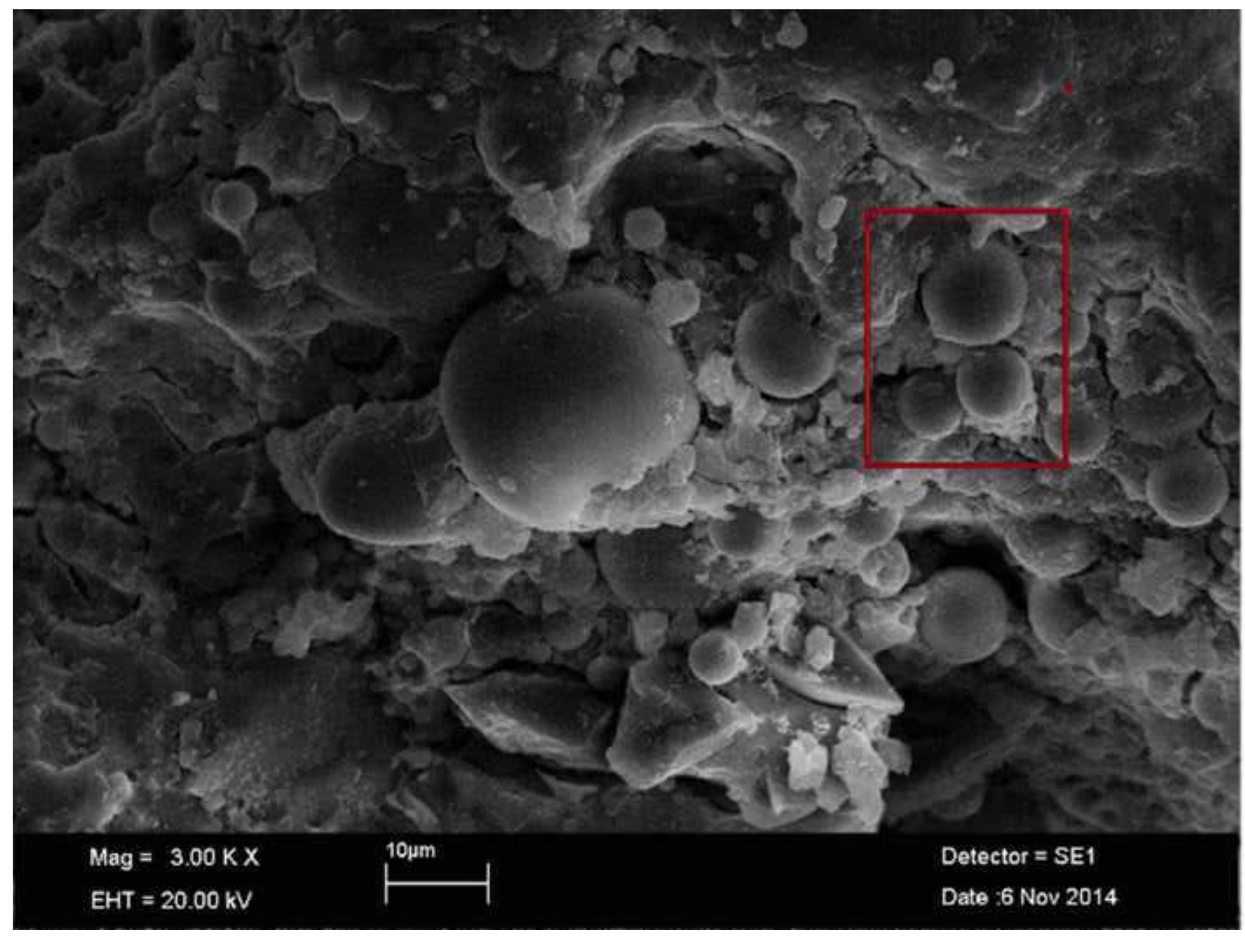

Fig. 12c

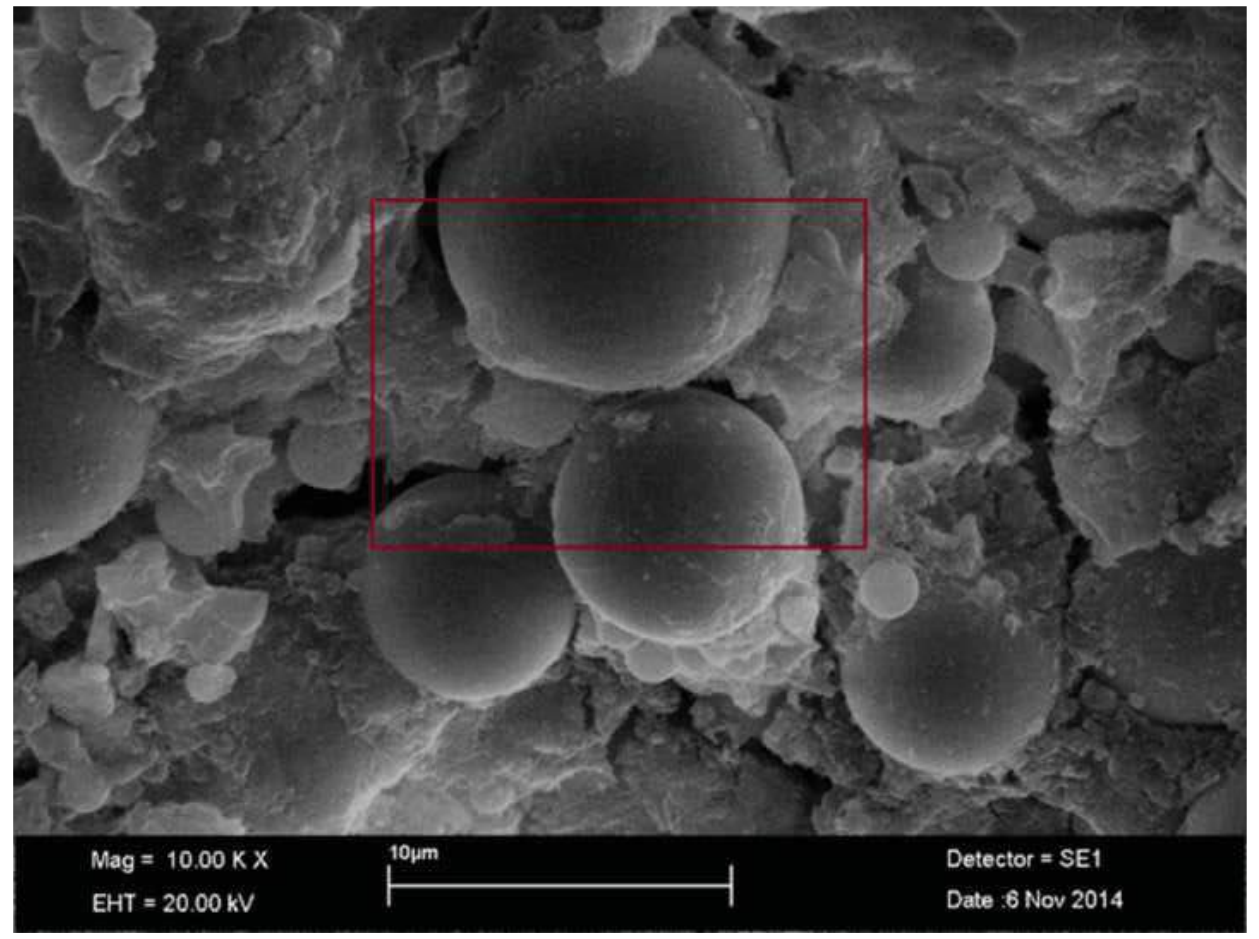

Fig. 12d 


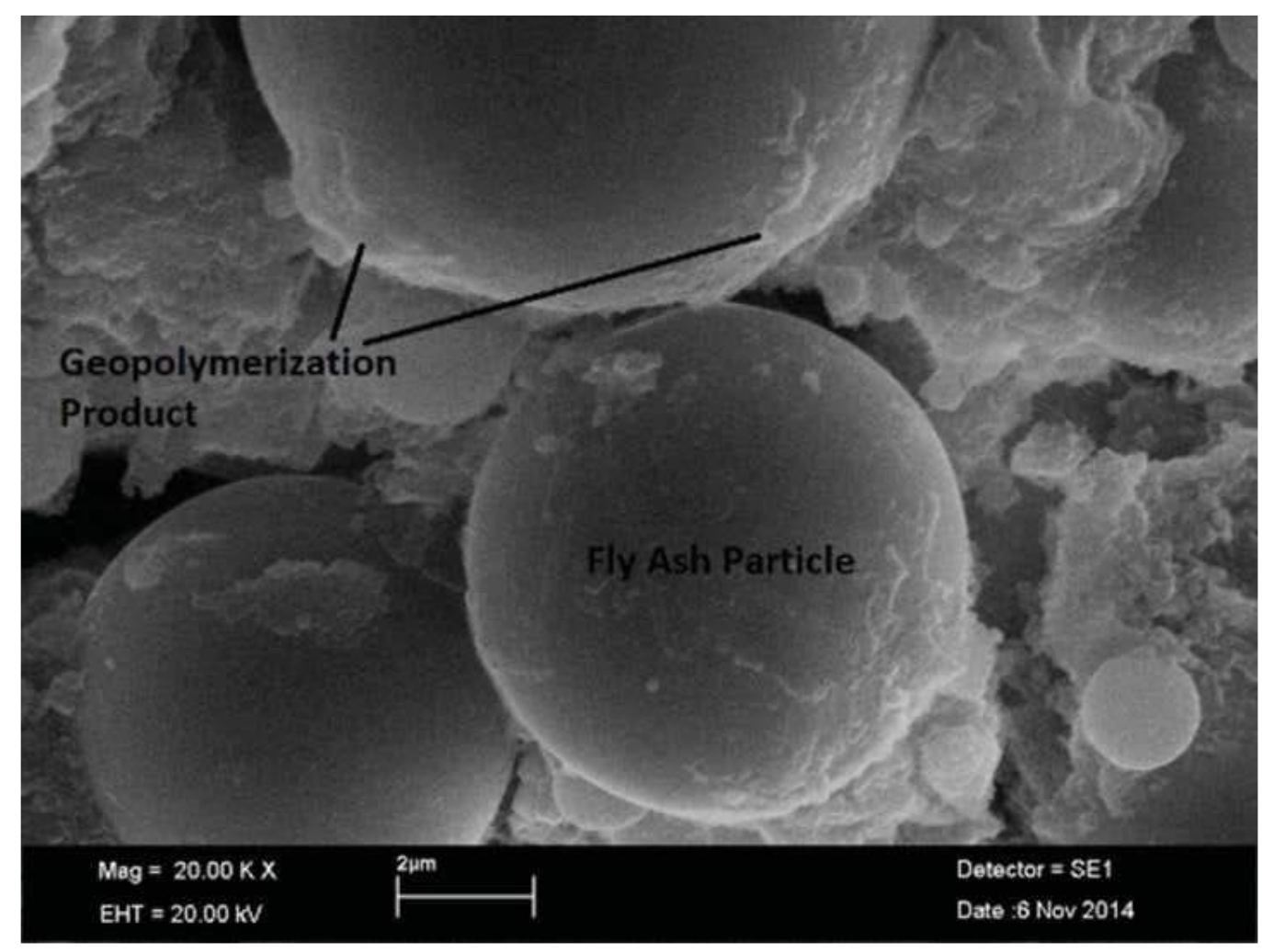

Fig. 12e

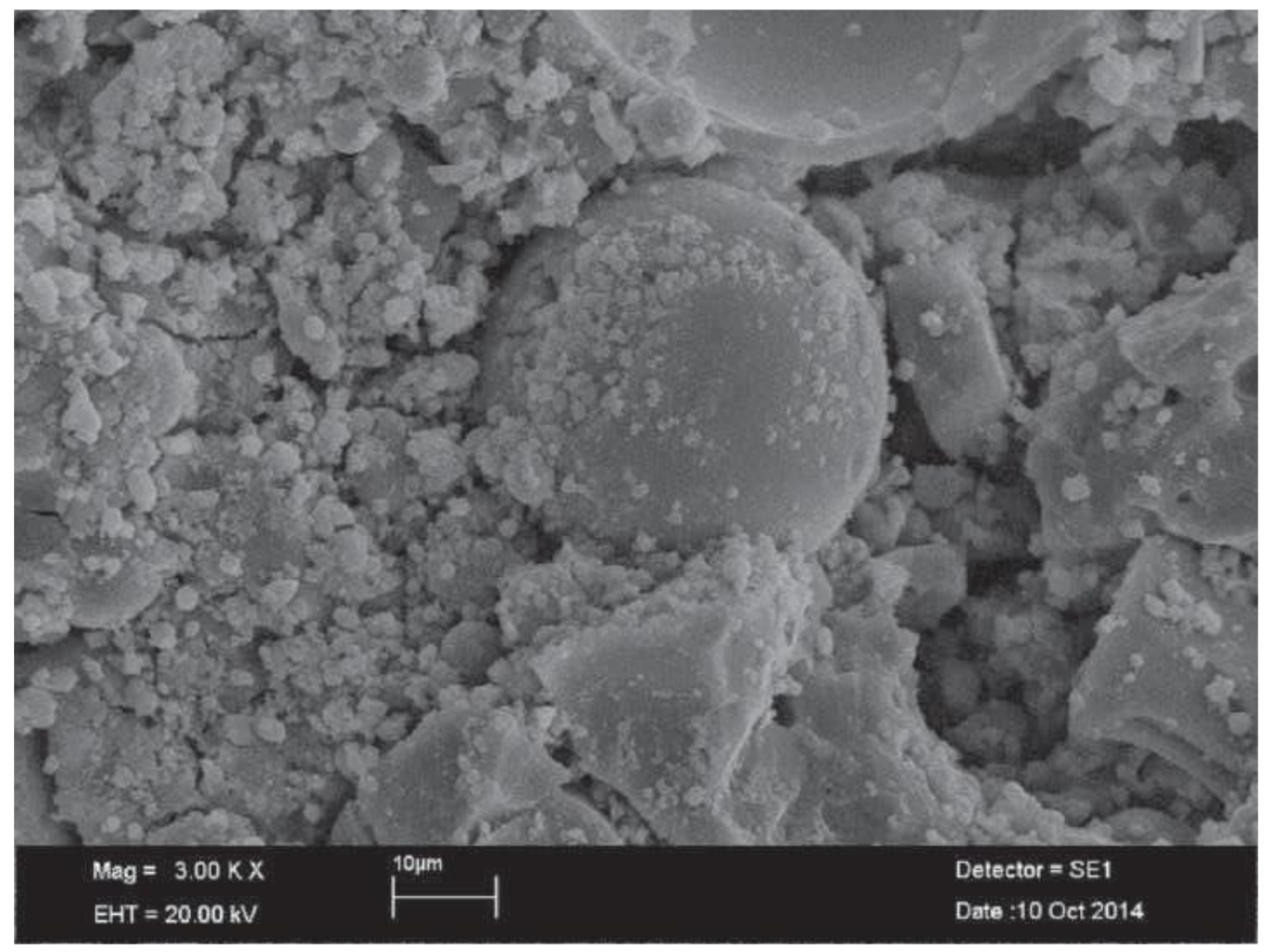

Fig. 13a 


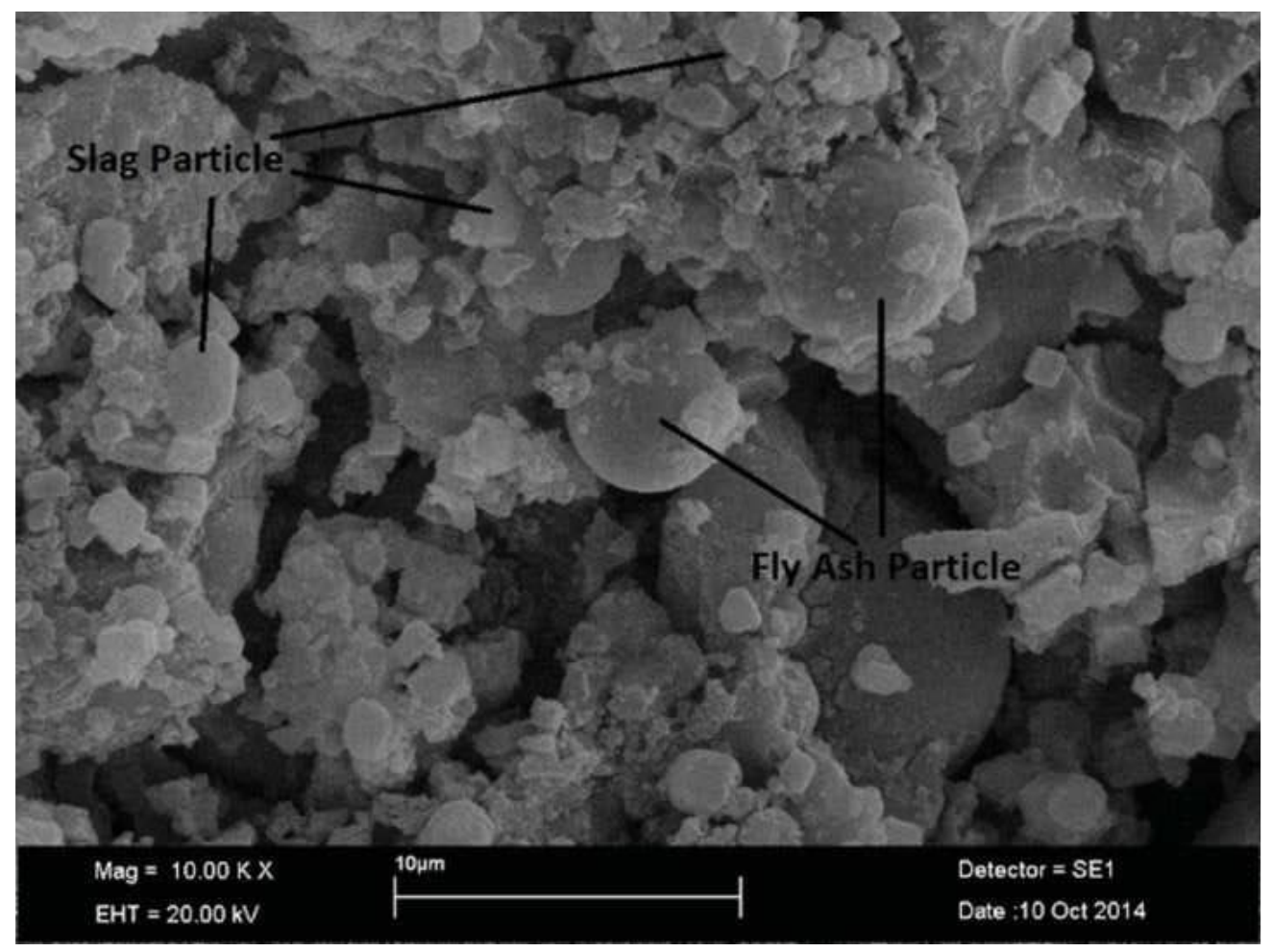

Fig. $13 b$

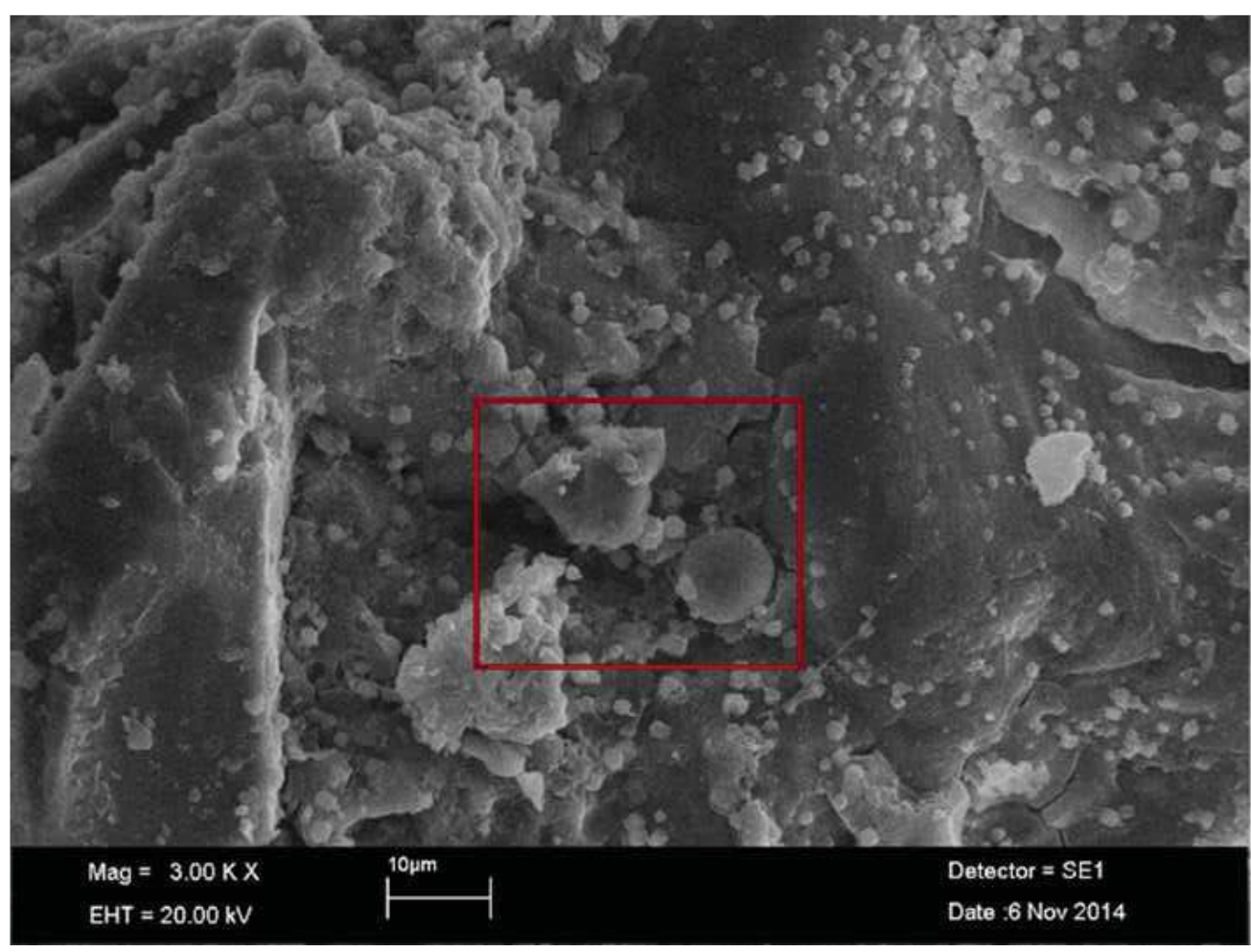

Fig. 13c 


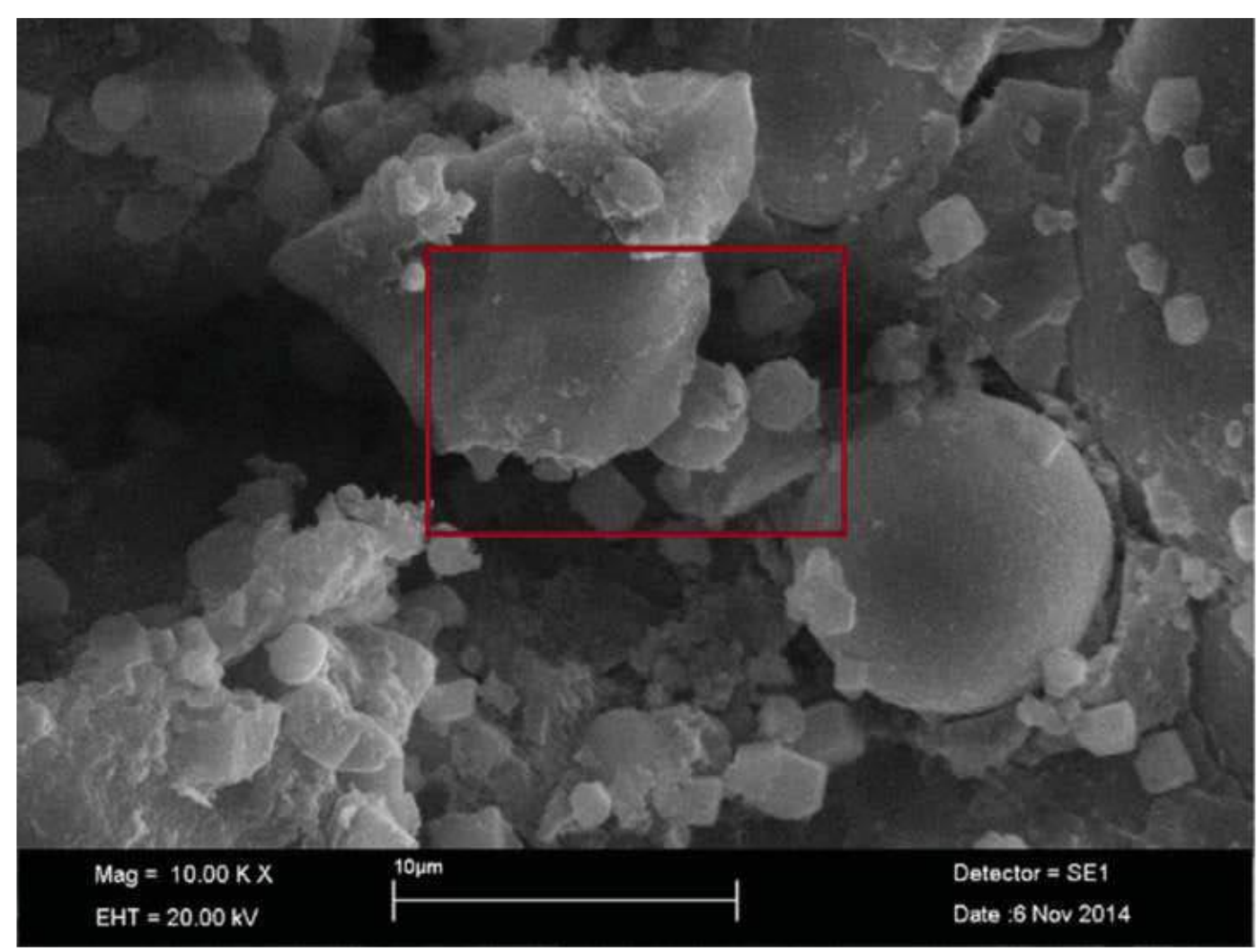

Fig. $13 d$

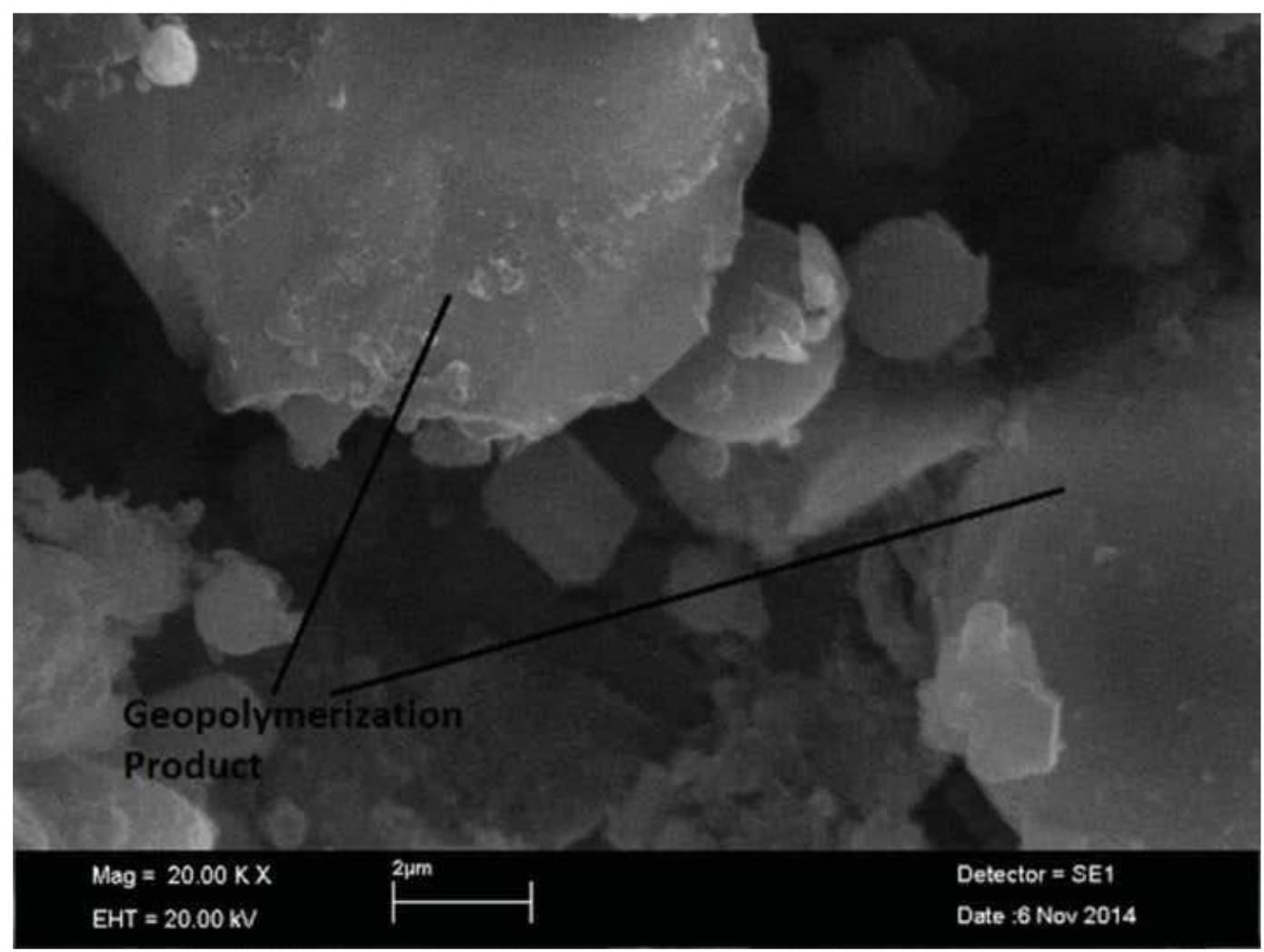

Fig. 13e 


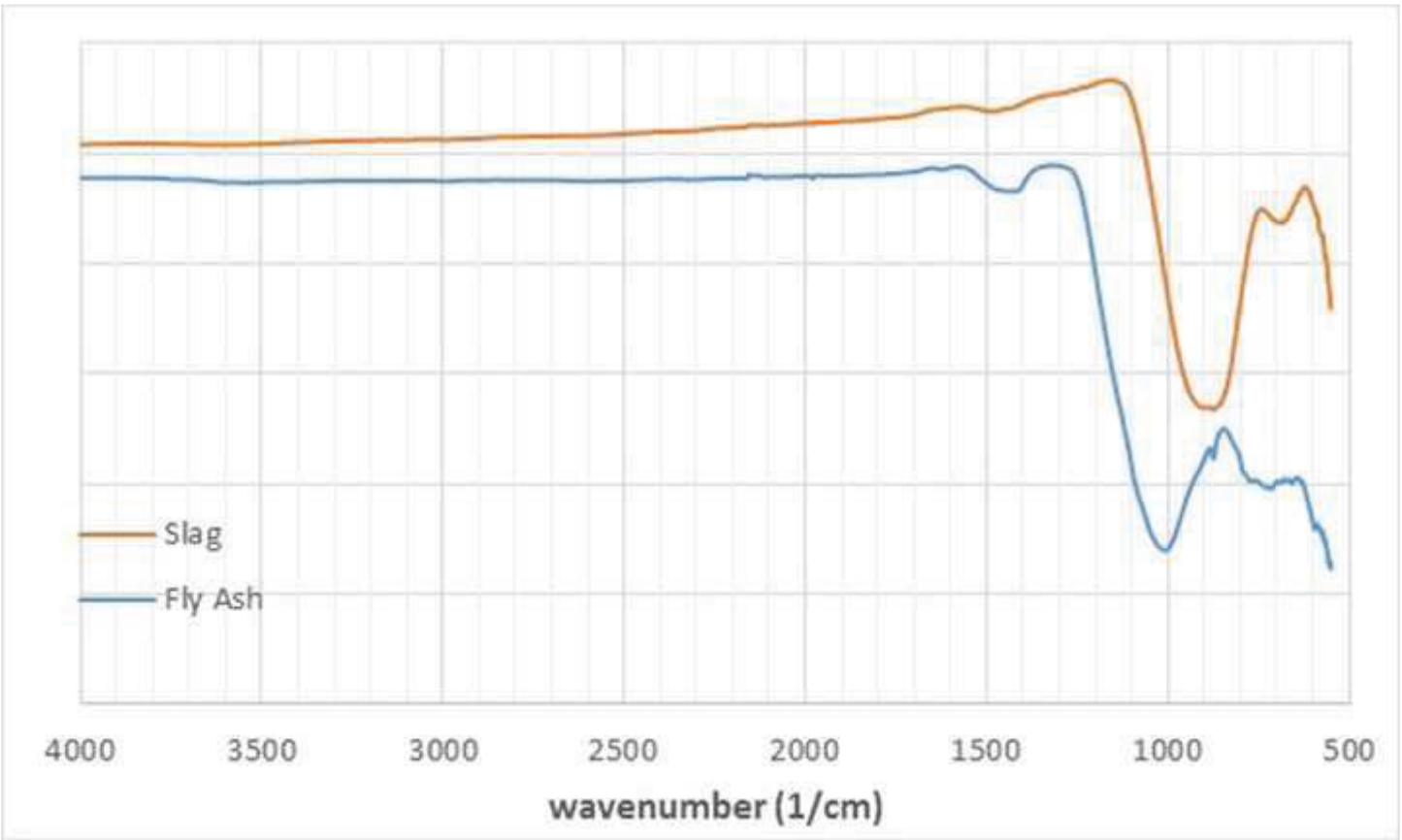

Fig. 14a

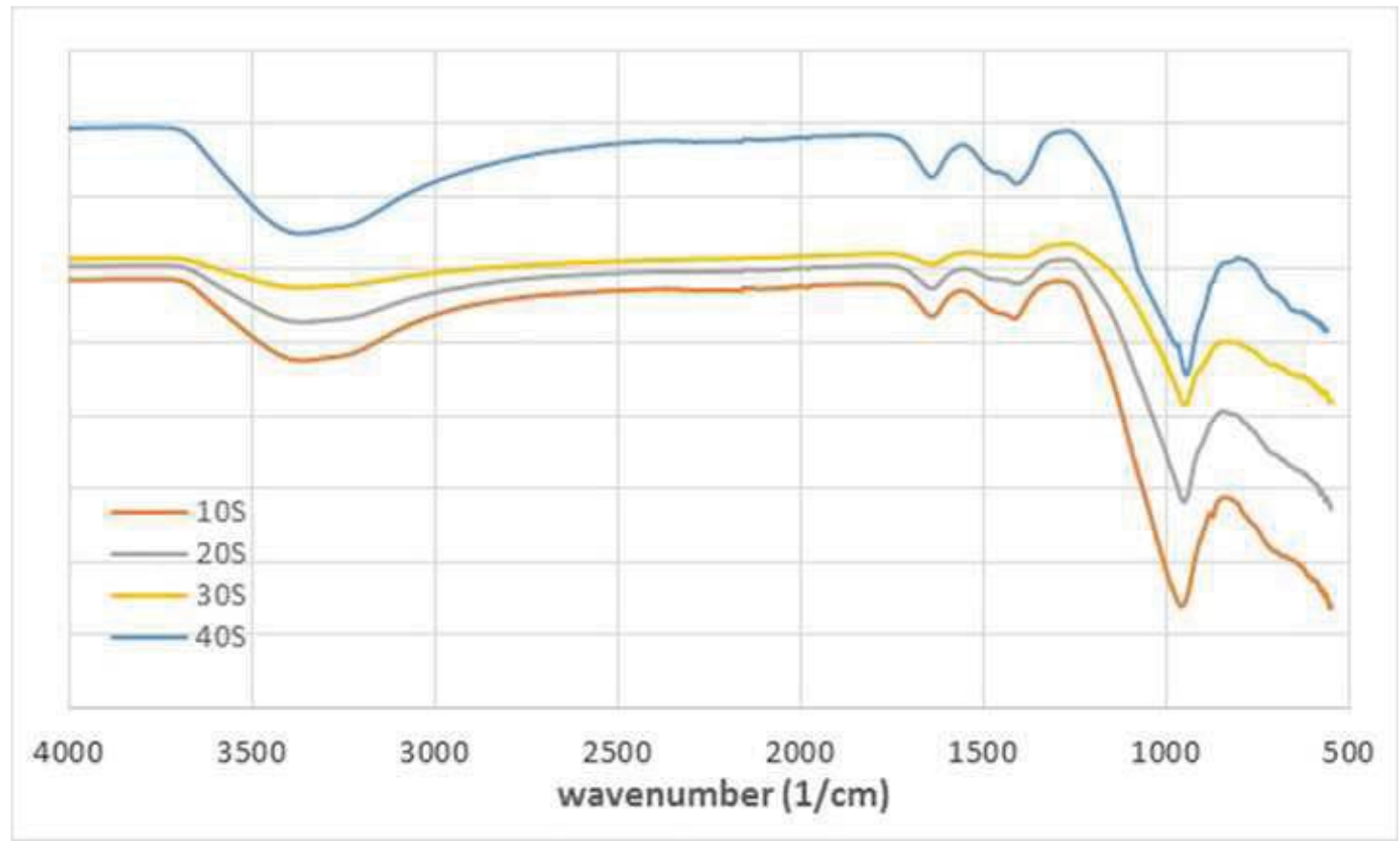

Fig. 14b 


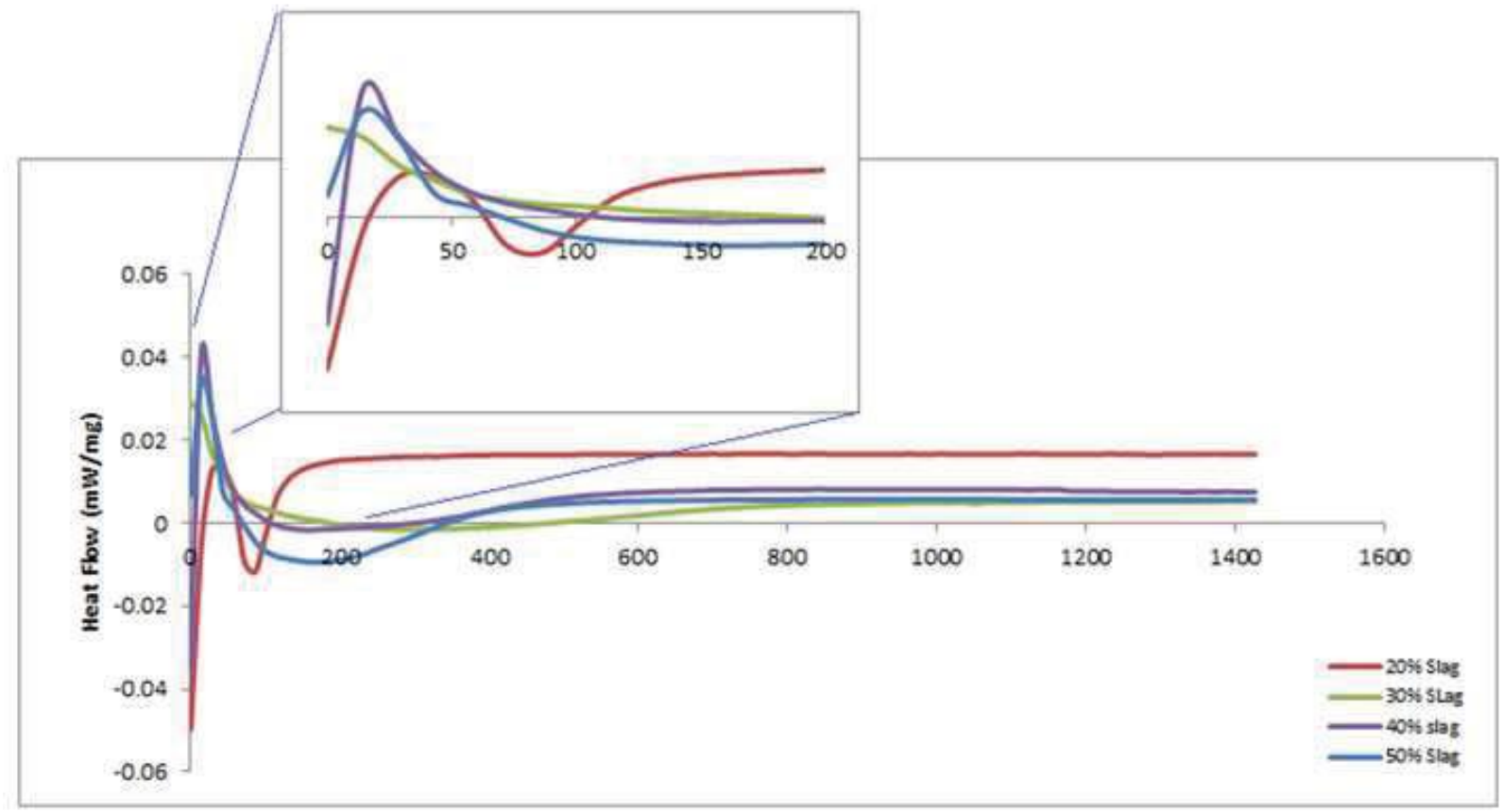

Fig. 15 